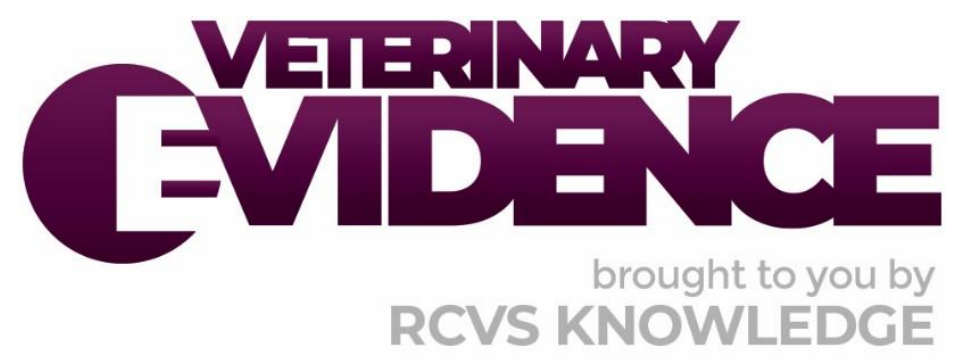

\title{
Can dog appeasing pheromone ameliorate stress behaviours associated with anxiety in mature domestic dogs?
}

\section{A Knowledge Summary by}

Chun Fung Wong DVM candidate ${ }^{1^{*}}$

Merran Govendir PhD BVSc MEd(Higher Ed) FHERDSA ${ }^{1}$

\footnotetext{
${ }^{1}$ Sydney School of Veterinary Science, The University of Sydney, Australia

* Corresponding Author (cwon3805@uni.sydney.edu.au)
}

ISSN: 2396-9776

Published: 14 Dec 2021

in: The Veterinary Evidence journal Vol 6, Issue 4

DOI: https://doi.org/10.18849/ve.v6i4.421

Reviewed by: Claire Corridan (BVMS PhD MRCVS MVCI) and Maureen O'Mara (PhD MGIS) 


\section{KNOWLEDGE SUMMARY}

\section{PICO question}

Does use of dog-appeasing pheromone reduce the frequency and/or severity of non-specific stress behaviours associated with anxiety in domestic dogs, older than 6 months, when compared with no treatment?

\section{Clinical bottom line}

\section{Category of research question}

Treatment

\section{The number and type of study designs reviewed}

Eight controlled trials were appraised. Four were randomised and four were either non-randomised or did not clearly describe the method of allocating subjects into treatment groups

\section{Strength of evidence}

Weak

\section{Outcomes reported}

There was no evidence that any dog appeasing pheromone (DAP) formulation (spray, diffuser, or collar) was superior. There was moderate evidence that DAP could reduce some behavioural manifestations of fear and/or anxiety stemming from thunderstorm noise and weak evidence that it could ameliorate some nonspecific stress behaviours in hospitalised patients. In shelter dogs, there was mild evidence that DAP could reduce barking intensity and increase some behaviours associated with relaxation. When behavioural changes occurred, most were observed during exposure to DAP and there were minimal residual effects post-treatment

\section{Conclusion}

The evidence for using DAP to manage stress behaviours associated with anxiety in dogs over six months of age remains weak. Until there is a stronger evidentiary basis, clinicians should be aware that a true clinical benefit is undetermined. Nevertheless, DAP is unlikely to cause harm and may still provide some therapeutic benefit. Therefore, DAP may still be employed in a multimodal management plan for some behaviour cases and may exert a placebo effect. However, if an owner's financial resources are restrictive, clinicians should not prioritise pheromone therapy at the omission of other therapies that have established clinical effects

\section{How to apply this evidence in practice}

The application of evidence into practice should take into account multiple factors, not limited to: individual clinical expertise, patient's circumstances and owners' values, country, location or clinic where you work, the individual case in front of you, the availability of therapies and resources.

Knowledge Summaries are a resource to help reinforce or inform decision making. They do not override the responsibility or judgement of the practitioner to do what is best for the animal in their care. 


\section{Clinical Scenario}

During veterinary consults, dog owners are asking you, the veterinarian, about interventions that can be used to alleviate fear or anxiety related behaviours in their animals. You recognise that these situations are stressful for both patient and owner. There are several treatments in your arsenal such as psychotropic medications, behaviour modification and environmental management. In some mild cases, psychotropic medication is not warranted and in other situations, owners outright decline pharmaceuticals. You are beginning to note the growing interest from clients to trial other adjunctive therapies such as Adaptil ${ }^{\circledR}$ (Ceva Santé Animale, Libourne, France, previously D.A.P $\left.{ }^{\circledast}\right)$. As you have heard many anecdotal opinions, you decide to investigate the evidence base for its efficacy.

\section{The evidence}

Eight controlled trials were appraised. One controlled trial (Prior \& Mills, 2020) was excluded during eligibility assessment because the outcome variables were dog-cat interactions in a household rather than non-specific anxiety-related behaviours exhibited in a dog. Overall, three studies investigated DAP spray (Amaya et al., 2020; Hermiston et al., 2018; and Siracusa et al., 2010), three investigated DAP collar (Broach \& Dunham, 2016; Grigg \& Piehler, 2015; and Landsberg et al., 2015) and two investigated a DAP diffuser (Taylor et al., 2020; and Kim et al., 2010). Most studies had relatively small samples sizes $(n=8-51)$ and did not report the concentration of DAP (Hermiston et al., 2018; Grigg \& Piehler, 2015; Landsberg et al., 2015; and Kim et al., 2010). When reported, there were inconsistencies in DAP concentration between formulations (Amaya et al., 2020; Taylor et al., 2020; Broach \& Dunham, 2016; and Siracusa et al., 2010), and even within the same formulation between different studies (Amaya et al., 2020; and Siracusa et al., 2010).

All three studies investigating the spray formulation were conducted in an animal shelter. The study with the highest quality design (Siracusa et al., 2010) was randomised, semi-blinded and placebo-controlled. However, the random allocation sequence was provided by the pheromone's manufacturer and the method by which this sequence was generated was not described. A second study (Amaya et al., 2020) was randomised, although the random generation method was not described. It was unblinded, not placebo-controlled, had multiple missed observations and the proximity by which treatment and placebo groups were housed may have biased results. The third study (Hermiston et al., 2018) provided the poorest evidential value as it was a non-randomised, crossover study that was not placebo-controlled. There was incomplete blinding of the assessor, inherently unblinded caregivers and a very short washout period that may or may not have obscured treatment effects. Additionally, the authors acknowledged that the observation period may have been too short (10 seconds) to detect potential significant effects. The findings reported by these three studies were inconsistent.

In those studies that investigated a DAP-infused collar, the most well-designed (Broach \& Dunham, 2016) assessed its application for 7 month old Belgian Malinois dogs transitioning to a military kennel. This was a double-blinded, randomised and placebo-controlled trial, however the generation of the random allocation sequence was not described. Importantly, the method by which the researchers calculated their outcome variables may have obscured potential treatment effects. A second study (Landsberg et al., 2015) was nonrandomised, double-blinded, and placebo-controlled, investigating the effect of the DAP collar on behaviour in response to thunderstorm audio in middle to older aged Beagles. The study design was robust because it controlled for breed, prevented cross-exposure of pheromone between intervention groups by spatial separation, and was conducted in a controlled facility that minimised external sources of bias. However, allocation of subjects was not randomised and there were perceived conflicts of interest. The third study (Grigg \& Piehler, 2015) assessed the impact of DAP collar on stress-related behaviours in dogs housed in a teaching kennel environment. This was a randomised controlled trial; however, the randomisation technique was not described, the sample size was small $(n=8)$, a placebo was not employed, and it was unclear if caregivers were blinded. Dogs were also concurrently used for teaching purposes that varied between subjects, a possible source of confounding bias. The results reported from these three studies were inconsistent. 
Two studies investigated a DAP-diffuser. The most well-designed (Taylor et al., 2020) assessed the effect of DAP on the behaviour of dogs during separation from their owner in a laboratory environment. A placebocontrolled repeated measures design was used, and both caregiver and assessor were blinded. However, the trial did not control for a time effect and may be biased by an order effect due to a failure to counterbalance. The second study investigated the effect of a DAP diffuser on separation-related behaviours for dogs with a variety of co-morbidities in a veterinary hospital (Kim et al., 2010). This publication did not report whether allocation of subjects to treatment groups were random and had inadequate reporting of their methodology such that it was unclear how some results were obtained. There were many uncontrolled confounding factors due to multiple disease diagnoses which necessitated differences in caregiving. In both studies, it is unclear if the DAP diffuser was used as per the manufacturer's instructions.

\section{Summary of the evidence}

Taylor et al. (2020)

\begin{tabular}{|c|c|}
\hline Population: & $\begin{array}{l}\text { Dogs and their owner (or a familiar person) were recruited via social } \\
\text { media. } \\
\text { - Age: mean }=8.1 \text { years, range }=4.0-12.1 \text { years. } \\
\text { - Neuter status: nine neutered, one entire. } \\
\text { - Breed: various. } \\
\text { - Sex: seven males, three females. }\end{array}$ \\
\hline Sample size: & 10 dogs. \\
\hline Intervention details: & $\begin{array}{l}\text { 4x diffusers (Ceva Santé Animale, } 2 \% \text { ) were placed in the corners of } \\
\text { a } 7.3 \mathrm{~m} \text { x } 6.4 \text { m laboratory with no furnishings. } \\
\text { - Treatment period: DAP diffuser switched on. } \\
\text { All subjects experienced the treatment period first, followed by } \\
\text { placebo period approximately } 2 \text { days later. } \\
\text { Each testing period (treatment and placebo) followed the same } \\
\text { format: } \\
\text { - 'Control': upon arrival, all subjects remained in the } \\
\text { laboratory for } 5 \text { minutes in the absence of their } \\
\text { owner/familiar person. This was to allow the subject to } \\
\text { habituate to the novel environment. } \\
\text { 'Condition A': owner/familiar person present with the } \\
\text { subject for } 5 \text { minutes. } \\
\text { 'Condition B': subject remained in the laboratory in the } \\
\text { absence of their owner/familiar person for } 30 \text { minutes with } \\
\text { DAP diffusers switched on or off (depending on the testing } \\
\text { period). } \\
\text { 'Condition C': owner/familiar person returned and stayed } \\
\text { with the subject for } 5 \text { minutes. }\end{array}$ \\
\hline Study design: & Controlled repeated measures design. \\
\hline Outcome studied: & $\begin{array}{l}\text { Physiological parameters were assessed but are irrelevant for this } \\
\text { Knowledge Summary. }\end{array}$ \\
\hline
\end{tabular}




\begin{tabular}{|c|c|}
\hline & 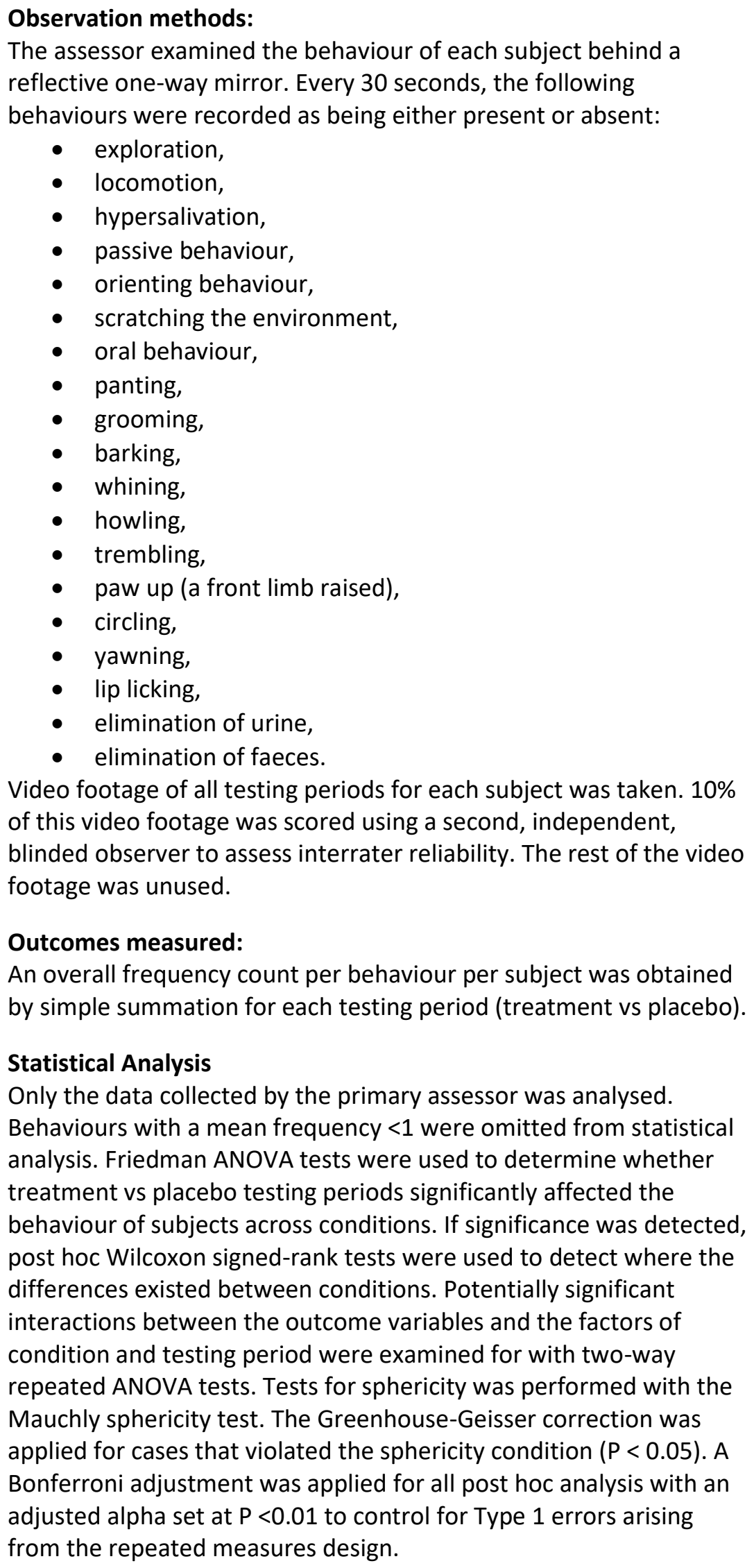 \\
\hline $\begin{array}{l}\text { Main findings: } \\
\text { (relevant to PICO question): }\end{array}$ & $\begin{array}{l}\text { - Hypersalivation, oral behaviour, panting, grooming, howling, } \\
\text { trembling, paw up and circling were all excluded from } \\
\text { analysis due to mean frequencies }<1 \text {. }\end{array}$ \\
\hline
\end{tabular}




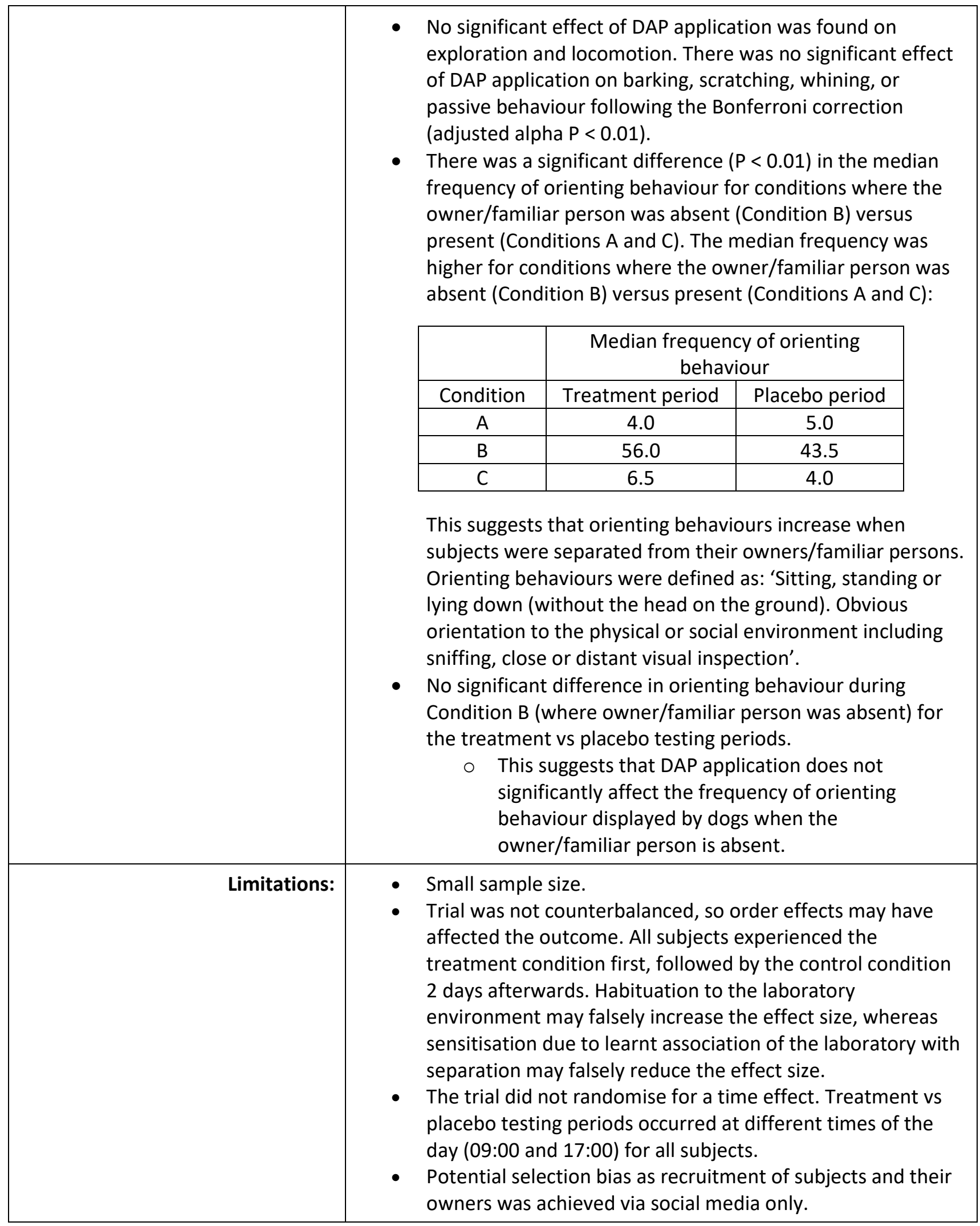

Amaya et al. (2020)

Population: Shelter dogs with 'high arousal-related behaviours' (such as air snapping, mouthing, attempts to bite lead or handler, excessive activity, constant vocalisation, and over-reaction to other dogs).

- Age: mean $=3.2$ years, range $=0.5$ to 11 years. 


\begin{tabular}{|c|c|}
\hline & $\begin{array}{l}\text { - Neuter status: all neutered. } \\
\text { - Breed: most cross-bred, few pure-breds. } \\
\text { - Gender: } 35 \text { males, } 25 \text { females. } \\
\text { - Length of residency: 8-150 days. }\end{array}$ \\
\hline Sample size: & $\begin{array}{l}60 \text { dogs: } \\
\text { - However, effective sample size for this PICO question is } n= \\
31 \text { (sum of subjects in the DAP group + control group, see } \\
\text { intervention details below). }\end{array}$ \\
\hline Intervention details: & 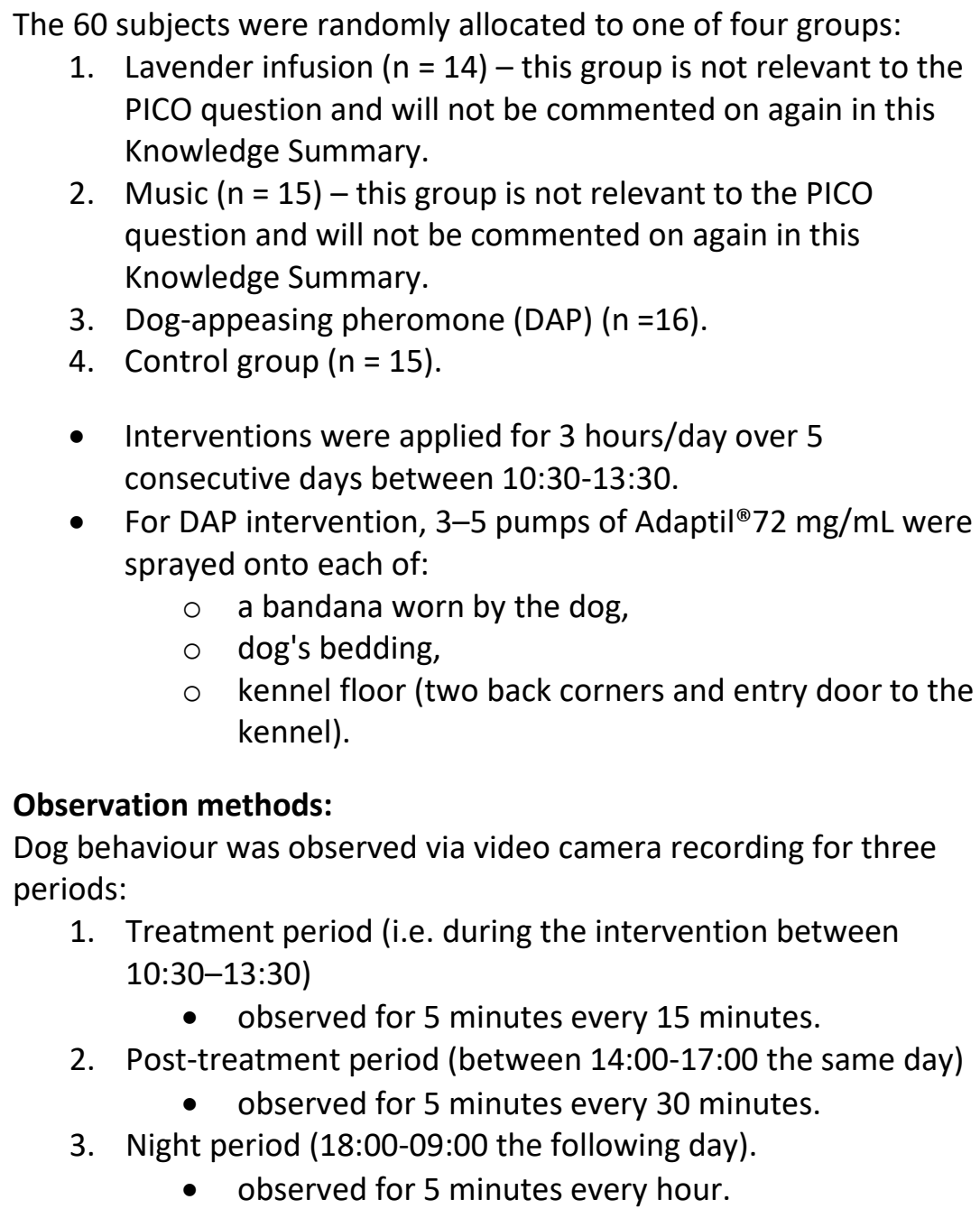 \\
\hline Study design: & Randomised, controlled trial. \\
\hline Outcome studied: & $\begin{array}{l}\text { Outcomes measured } \\
\text { Each of the following behaviours were expressed as a proportion of } \\
\text { total time observed (\%) (except where indicated): lie down total, } \\
\text { head-up and head-down; standing; walking; standing at the exit } \\
\text { door; wall/door bounce; sitting; vocalisation; body shake (quantified } \\
\text { as events per hour); sniffing ground; grooming; drinking; panting; } \\
\text { yawning (quantified as events per hour); urination / defecation; } \\
\text { playing with objects; } \\
\text { - tail position: } \\
\circ \text { Low: }-30 \text { to }-90^{\circ} \text { from horizontal } \\
\circ \text { Medium/high: }-30 \text { to } 90^{\circ} \text { from horizontal }\end{array}$ \\
\hline
\end{tabular}




\begin{tabular}{|c|c|}
\hline & $\begin{array}{l}\text { tail: } \\
\begin{array}{l}\circ \text { moving } \\
\circ\end{array} \\
\circ \text { not moving } \\
\circ \text { location of dog in kennel: } \\
0 \text { at back third } \\
\circ \text { at middle third } \\
\circ \text { in crate ( } \geq 50 \% \text { of the body within the crate). } \\
\text { NOTE: it is unclear what the behaviour 'wall/door bounce' refers to. } \\
\text { Statistical Analysis: } \\
\text { A mixed effects model was constructed with each dog, entry time to } \\
\text { the study, treatment and day as fixed factors. Square root } \\
\text { transformations were used to secure normal distribution for some } \\
\text { residuals. When significant treatment differences were detected, a } \\
\text { Tukey's test was used to further analyse these differences. For some } \\
\text { behaviours with insufficient data, a generalised linear model was } \\
\text { used to assess treatment effects, with dog number and treatment as } \\
\text { fixed factors. }\end{array}$ \\
\hline $\begin{array}{l}\text { Main findings: } \\
\text { (relevant to PICO question): }\end{array}$ & 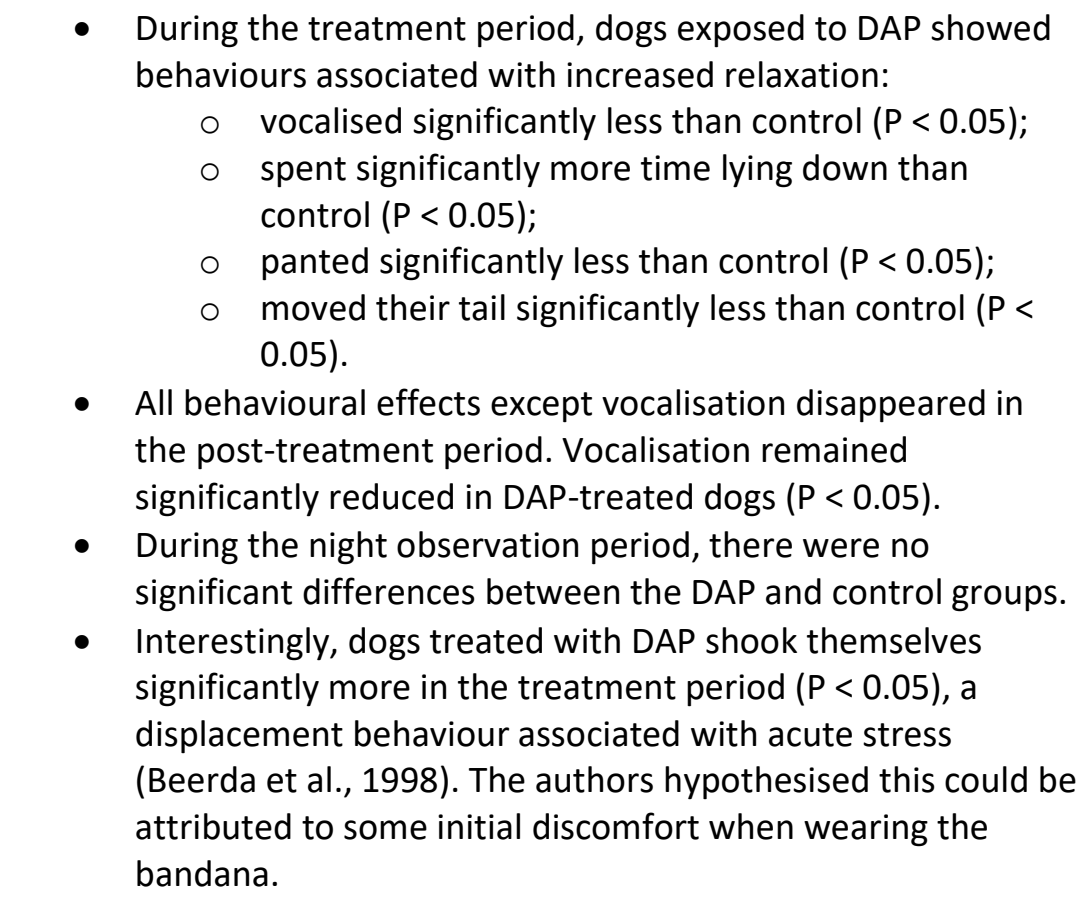 \\
\hline Limitations: & $\begin{array}{l}\text { Missed observations comprised } 0.5 \% \text { of total observations } \\
\text { during the treatment period, } 11.8 \% \text { for the post-treatment } \\
\text { period, and } 16.3 \% \text { for the night period. These were treated } \\
\text { as missing values. Because this reduces statistical power, } \\
\text { confidence in the accuracy of results for the post-treatment } \\
\text { and night periods was reduced. } \\
\text { - Short length of each observation and large gaps between } \\
\text { each observation may have reduced statistical power. } \\
\text { - No sample size calculation. } \\
\text { - Small sample size. } \\
\text { - Method of generating randomisation sequence not } \\
\text { - Lescribed. }\end{array}$ \\
\hline
\end{tabular}




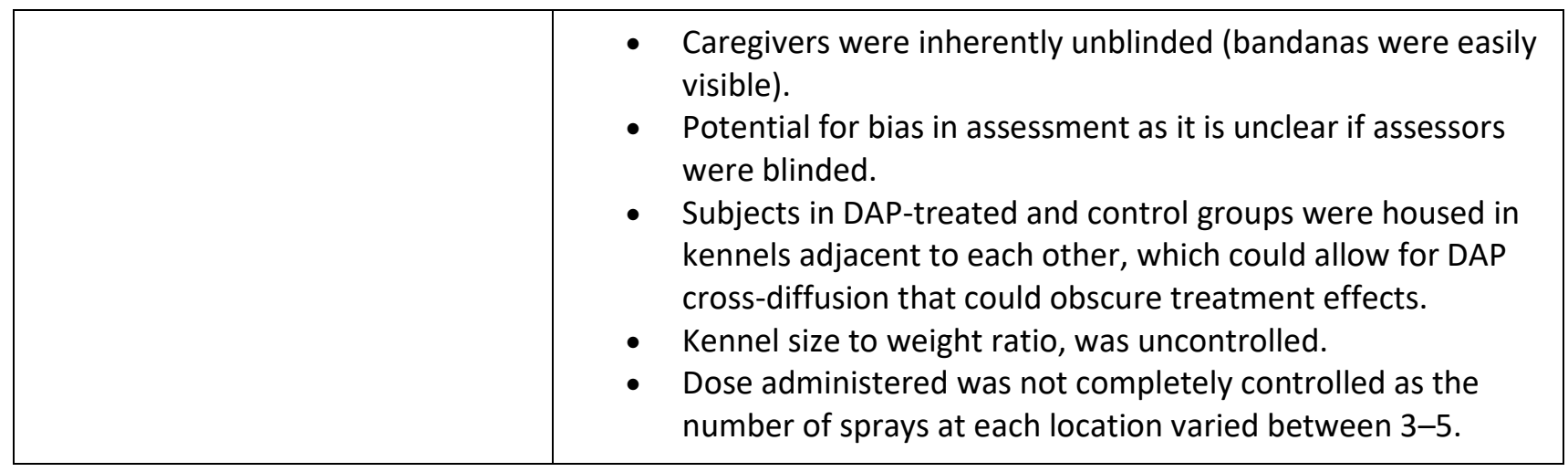

\begin{tabular}{|c|c|}
\hline \multicolumn{2}{|l|}{ Hermiston et al. (2018) } \\
\hline Population: & $\begin{array}{l}25 \text { shelter dogs: } \\
\text { - Age: mean }=41.64 \text { months, range }=5-168 \text { months } \\
\text { - Neuter status: } 22 \text { neutered, three entire } \\
\text { - Breed: various } \\
\text { - Gender: } 16 \text { males, nine females } \\
\text { A single subject was below the } 6 \text { month cut-off for this Knowledge } \\
\text { Summary, however this study is included as } 24 / 25 \text { dogs were }>6 \\
\text { months of age. }\end{array}$ \\
\hline Sample size: & 25 dogs. \\
\hline Intervention details: & $\begin{array}{l}\text { - Treatment condition: Two pumps of DAP spray (Adaptil }{ }^{\circledR} \text {, } \\
\text { dose not provided) applied to four corners of a kennel, } 30 \\
\text { minutes prior to observation periods. } \\
\text { - Control condition: no DAP exposure. } \\
\text { Each subject experienced the treatment condition and control } \\
\text { condition on consecutive days. It is assumed that each condition } \\
\text { lasted for a single day. } \\
\text { - } \mathrm{n}=12 \text { dogs (seven females, five males) experienced the } \\
\text { treatment condition first. } \\
\text { - } \quad \mathrm{n}=13 \text { dogs (two females, } 11 \text { males) experienced the control } \\
\quad \text { condition first. } \\
\text { Larger dogs, plus dogs that were deemed by shelter staff as having } \\
\text { displayed high levels of stress-associated behaviour were housed in } \\
\text { larger kennels measuring } 2.7 \times 5.6 \text { m. All other dogs were housed in } \\
\text { kennels with dimensions measuring } 1.5 \times 2.7 \text { m. } \\
\text { Observation methods: } \\
\text { For each condition, there were two observation periods each day at } \\
\text { 09:00 and } 17: 00 \text {. For each subject, an observation lasted } 10 \text { seconds } \\
\text { and involved walking a common unfamiliar dog past the subject's } \\
\text { kennel. An observation began when the unfamiliar dog reached } 1 \\
\text { metre in distance from a subject's kennel. }\end{array}$ \\
\hline Study design: & Non-randomised, controlled, crossover trial. \\
\hline Outcome studied: & $\begin{array}{l}\text { Outcomes measured: } \\
\text { - Mean barking intensity (quantified using a decibel meter). } \\
\text { - Frequency of barking. }\end{array}$ \\
\hline
\end{tabular}




\begin{tabular}{|c|c|}
\hline & $\begin{array}{l}\text { - Frequency of stress-related behaviours: } \\
\quad \text { low body posture, } \\
\circ \text { licking lips, } \\
\circ \text { yawning, } \\
\circ \text { panting, } \\
\circ \text { vocalisation, } \\
\circ \text { escape behaviour. } \\
\text { The assessor was not blinded to treatment allocation, but video files } \\
\text { were renamed prior to assessment to reduce observer bias. } \\
\text { Statistical analysis } \\
\text { - Mean barking intensity was calculated for treatment vs } \\
\text { control conditions. } \\
\text { An overall frequency count per behaviour was calculated for } \\
\text { Paired t-tests compared mean barking intensity for treatment versus } \\
\text { control. } \\
\text { Paired t-tests and Wilcoxon signed-rank tests assessed differences in } \\
\text { stress-related behaviours for treatment versus control. }\end{array}$ \\
\hline $\begin{array}{l}\text { Main findings: } \\
\text { (relevant to PICO question): }\end{array}$ & $\begin{array}{l}\text { DAP exposure led to significantly reduced mean barking intensity (P } \\
=0.002 \text { ), mean treatment effect }=-6.48 \text { decibels. } \\
\text { - Barking is a non-specific behaviour (Protopopova, 2016). A } \\
\text { reduction in barking intensity may not necessarily reflect a } \\
\text { reduction in stress or anxiety. } \\
\text { There was no significant treatment effect on other outcomes. The } \\
\text { authors note that the reduction in barking intensity was small and } \\
\text { may or may not be associated with a reduction in stress since all } \\
\text { other indicators of stress were not significantly different. }\end{array}$ \\
\hline Limitations: & 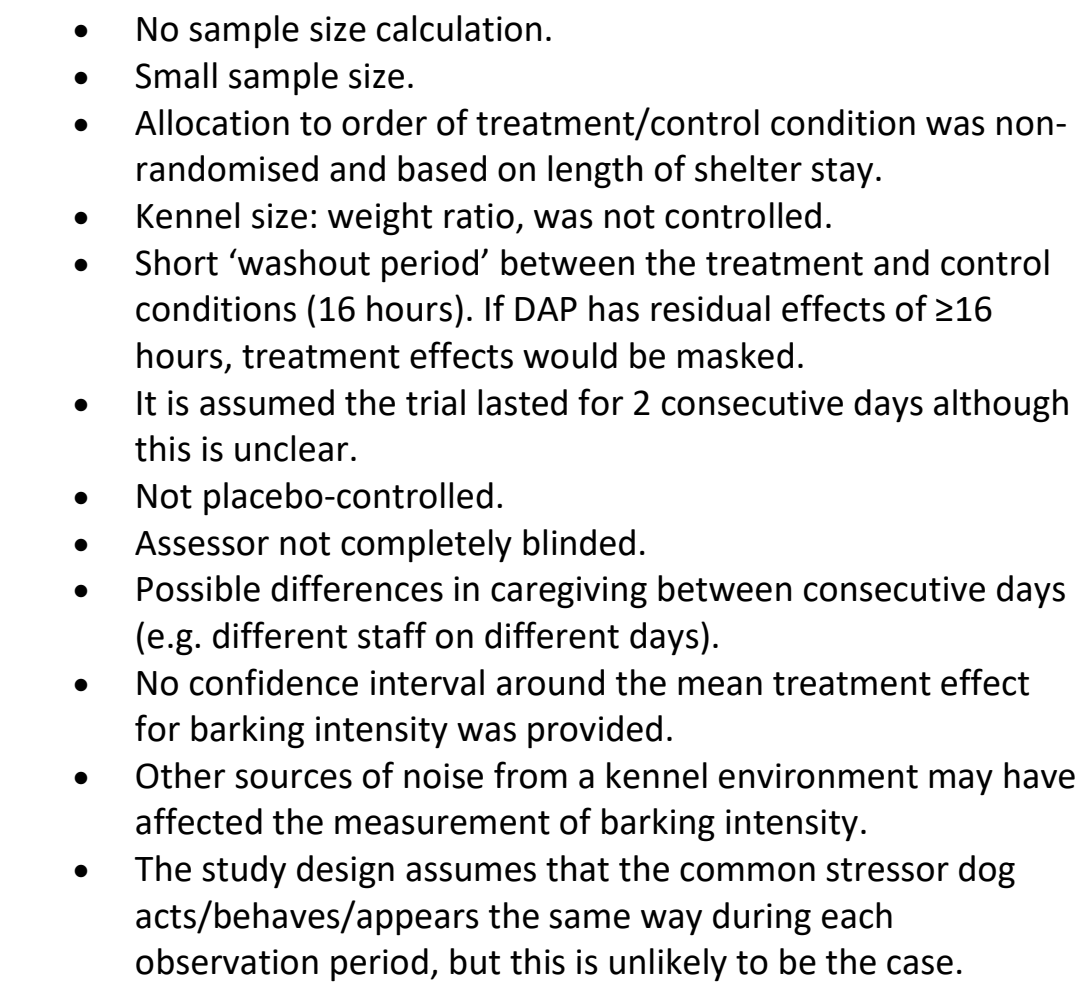 \\
\hline
\end{tabular}




\begin{tabular}{|l|l|}
\hline - & $\begin{array}{l}\text { The observation period (10 sec) may be too short to detect } \\
\text { any significant differences in the frequency of certain } \\
\text { behaviours - this was acknowledged by the authors. }\end{array}$ \\
\hline
\end{tabular}

\section{Broach \& Dunham (2016)}

\begin{tabular}{|c|c|}
\hline Population: & $\begin{array}{l}7 \text { month old Belgian Malinois dogs arriving at the Lackland Air Force } \\
\text { Base (AFB) Kennels. }\end{array}$ \\
\hline Sample size: & $\begin{array}{l}51 \text { ( } 54 \text { enrolled, two eliminated for medical reasons, one eliminated } \\
\text { due to scheduling issues). }\end{array}$ \\
\hline Intervention details: & 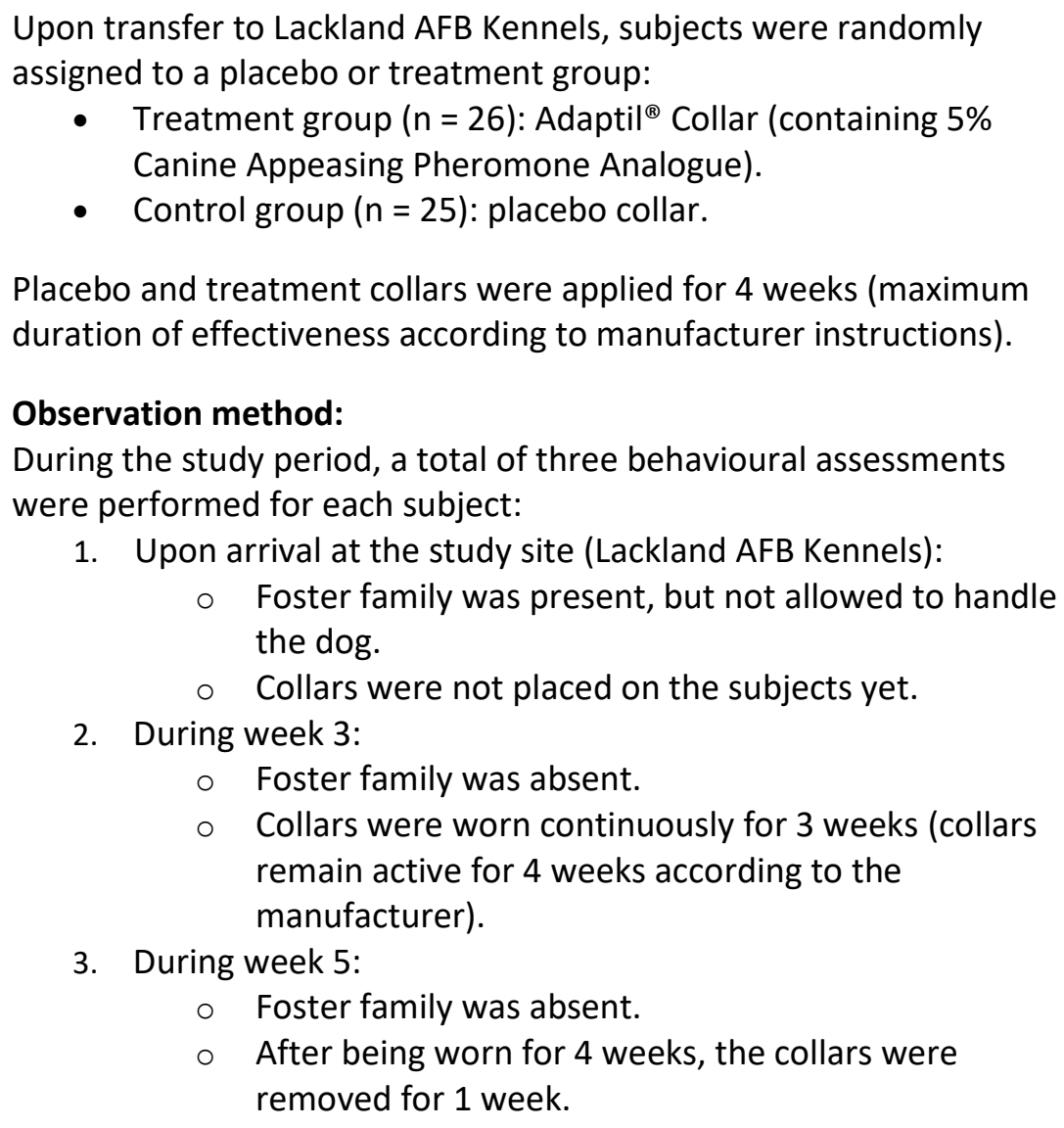 \\
\hline Study design: & Randomised, controlled trial. \\
\hline Outcome studied: & $\begin{array}{l}\text { Outcomes measured: } \\
\text { Each behavioural assessment investigated frequency and severity of } \\
\text { five categories of behaviour: activity level, aggression/affability, } \\
\text { response to handling, focus, and distress (e.g. signs of low body } \\
\text { posture, lip-licking, panting, escape behaviour, vocalisation, etc.). } \\
\text { Each behavioural category was scored via a pre-constructed 5-point } \\
\text { Likert scale. } \\
\text { Statistical Analysis relevant to PICO question: } \\
\text { A Welch T-test, and a 2-sided Wilcoxon exact test were performed } \\
\text { to compare the mean score for each behaviour factor between } \\
\text { treatment and control groups. } \\
\text { T-tests were also conducted to assess change in mean score for each } \\
\text { behaviour factor. 'Change' in mean score was calculated by }\end{array}$ \\
\hline
\end{tabular}




\begin{tabular}{|c|c|}
\hline & $\begin{array}{l}\text { subtracting the first (baseline) behavioural assessment score from } \\
\text { the final behavioural assessment score for each behaviour factor. }\end{array}$ \\
\hline (relevant to PICO question): & $\begin{array}{r}\text { The distress category, and the aggression/affability category is } \\
\text { relevant to this PICO question. } \\
\text { Limitations: }\end{array}$ \\
\hline $\begin{array}{l}\text { There was no significant treatment effect for any behaviour } \\
\text { category. }\end{array}$ \\
\hline $\begin{array}{l}\text { Three study subjects were eliminated due to health or } \\
\text { scheduling reasons. It is not stated if the researchers } \\
\text { proceeded with an intention-to-treat analysis. }\end{array}$ \\
$\begin{aligned} \text { Did not describe the method by which the random sequence } \\
\text { for allocating subjects was generated. } \\
\text { Behavioural assessments were based on subjective } \\
\text { measures. }\end{aligned}$ \\
\hline
\end{tabular}

\begin{tabular}{|c|c|}
\hline 2015) & \\
\hline Population: & $\begin{array}{l}\text { - } \quad \text { Age: } 7-12 \text { years. } \\
\text { - } \text { Neuter status: } 23 \text { neutered, one entire. } \\
\text { - } \text { Breed: all Beagles } \\
\text { - Gender: both sexes (specific numbers not included). }\end{array}$ \\
\hline Sample size: & 24 dogs. \\
\hline Intervention details: & $\begin{array}{l}\text { Treatment allocation for 'Testing Phase': } \\
\text { Subjects were ranked in decreasing order by their 'global } \\
\text { fear/anxiety score' (see below for how subjects were scored) to } \\
\text { a 'baseline thunderstorm session' (Test } 0 \text { ) and then alternately } \\
\text { allocated into treatment and control groups. } \\
\text { - Treatment Group: DAP Collar (Adaptil }{ }^{\circledR} \text {, dose not described) } \\
\text { ( } n=12 \text { ) } \\
\text { - Control Group: Placebo collar ( } n=12 \text { ) } \\
\text { Collars were worn by subjects until the conclusion of the testing } \\
\text { procedures. } \\
\text { Observation method: } \\
\text { Treatment and placebo groups were exposed to an audio recording } \\
\text { of thunderstorm sounds for } 9 \text { minutes a day for } 2 \text { days total (i.e. } \\
\text { 'test 1' and 'test 2'). } \\
\text { Subjects were video recorded during both tests: } \\
\text { - 'Test 1': began } 24 \text { hours after collars were fitted onto } \\
\text { subjects. } \\
\text { 0-3 minutes - no audio stimulation (assessed behaviour 'before } \\
\text { thunder exposure'). } \\
\text { 3-6 minutes - thunderstorm audio stimulation (assessed } \\
\text { behaviour 'during thunder exposure'). } \\
6-9 \text { minutes - no audio stimulation (assessed behaviour } \\
\text { 'following thunder exposure'). }\end{array}$ \\
\hline Study design: & rial. \\
\hline
\end{tabular}




\begin{tabular}{|c|c|}
\hline Outcome studied: & $\begin{array}{l}\text { Outcomes measured } \\
\text { Video recordings were reviewed by: } \\
\text { - A blinded observer, who assessed the behaviour of each } \\
\text { subject based on a pre-constructed 6-point scale for: } \\
\text { 'Active' fear/anxiety (based on running, scanning, } \\
\text { startling, digging, and jumping). } \\
\quad \text { 'Passive' fear/anxiety (based on freezing, cowering, } \\
\text { lip-licking, and trembling). } \\
\circ \quad \text { 'Global' fear/anxiety (combined active and passive). } \\
\text { A score of } 6 \text { represented high intensity behaviours performed at } \\
\text { high frequency whilst a score of } 0 \text { represented the opposite. } \\
\text { - A blinded technician, who assessed each subject for 'use of a } \\
\text { hide' during the test (dichotomous variable) as a coping } \\
\text { strategy - i.e. the using of a hiding place (polyethylene box } \\
\text { 58.4cm long x } 61 \mathrm{~cm} \text { wide x } 58.4 \mathrm{~cm} \text { high) as a coping } \\
\text { strategy. }\end{array}$ \\
\hline $\begin{array}{l}\text { Main findings: } \\
\text { (relevant to PICO question): }\end{array}$ & 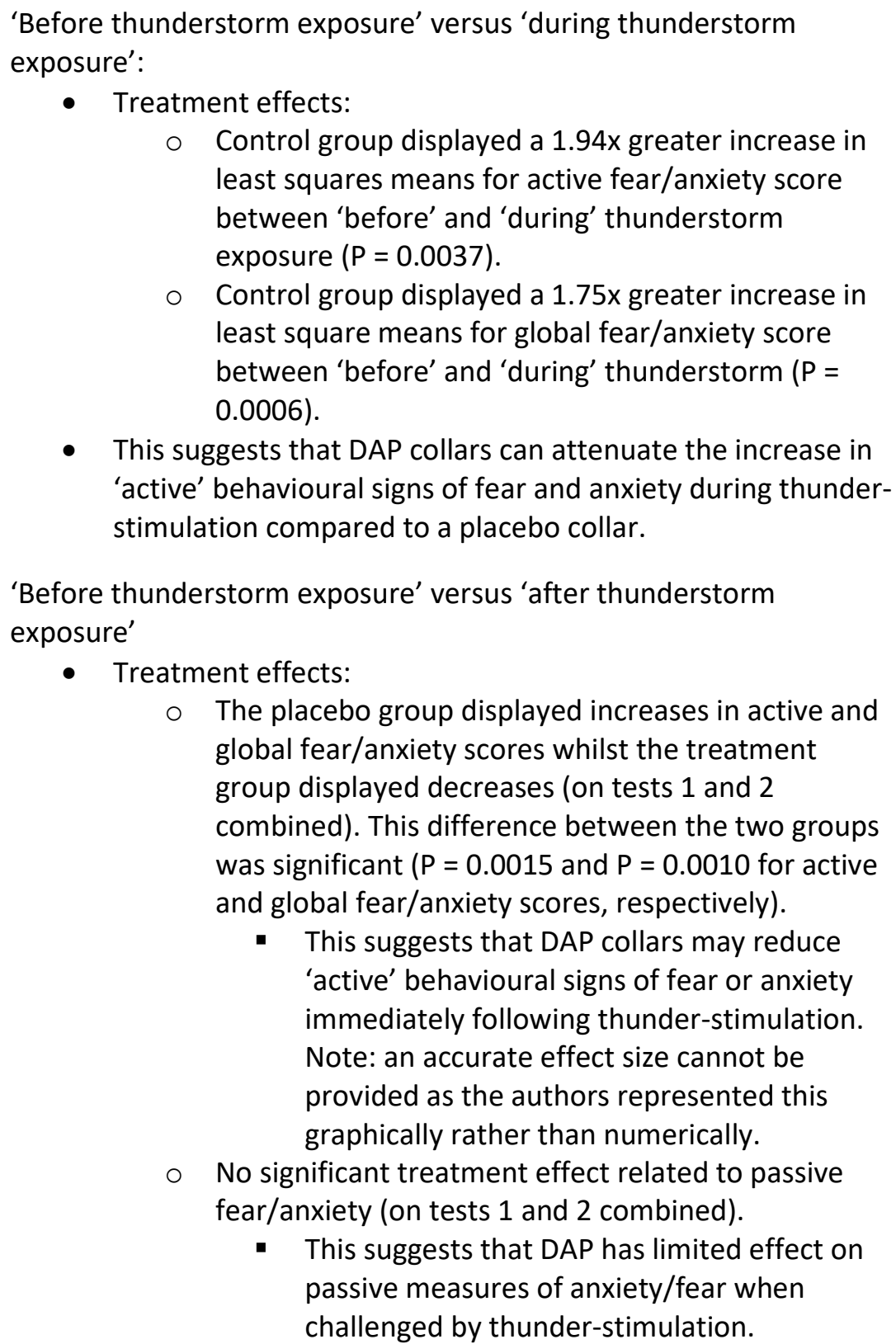 \\
\hline
\end{tabular}




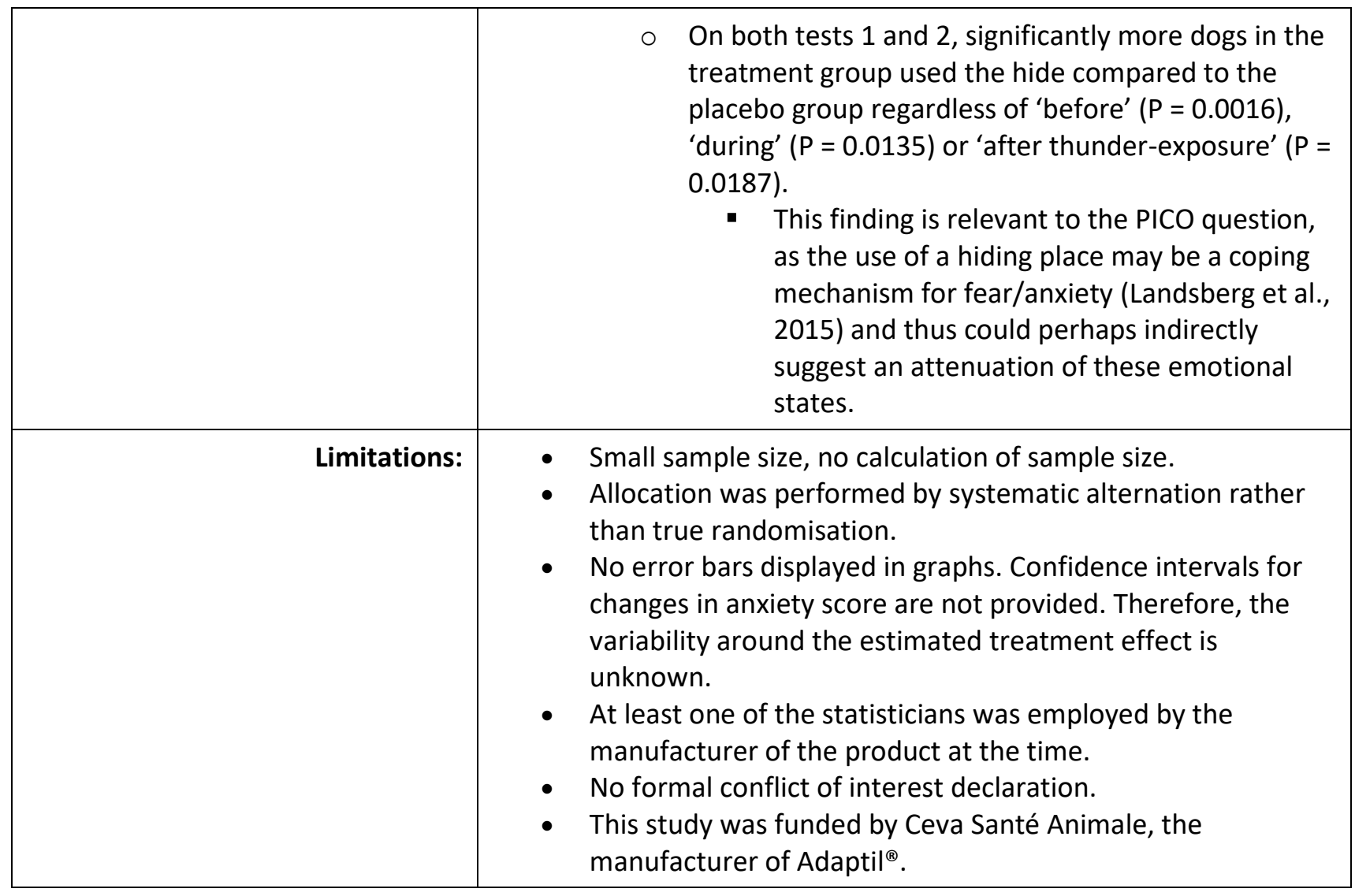

\begin{tabular}{|c|c|}
\hline \multicolumn{2}{|l|}{ Grigg \& Piehler (2015) } \\
\hline Population: & $\begin{array}{l}\text { Teaching dogs from the Ross University School of Veterinary } \\
\text { Medicine, St. Kitts \& Nevis colony of teaching dogs pre-identified as } \\
\text { exhibiting repetitive behaviours. Authors did not state how many } \\
\text { dogs were eligible for selection. } \\
\text { - Age: range }=2 \text { to }>6 \text { years, mean not provided. } \\
\text { - Neuter status: six neutered, two entire. } \\
\text { - Breed: no details provided. } \\
\text { - Gender: seven males, one female. } \\
\text { - Length of residency: } 2-24 \text { months. }\end{array}$ \\
\hline Sample size: & Eight dogs. \\
\hline Intervention details: & $\begin{array}{l}\text { Baseline behavioural data: } \\
\text { Subjects were initially filmed for } 20 \text { minutes each day over } 20 \text { days } \\
\text { to obtain baseline behavioural data. } \\
\text { Treatment allocation: } \\
\text { Subjects were randomly allocated into treatment and control } \\
\text { groups: } \\
\text { - Treatment: Adaptil }{ }^{\circledR} \text { Collar (DAP, dose not described, Ceva } \\
\text { - Santé Animale) }(n=6) \text {. } \\
\text { Observiol: no intervention, no placebo }(n=2) \text {. } \\
\text { During the treatment period, filming continued over the next } 21 \\
\text { days using the same schedule. Video observers (student research } \\
\text { assistants) were trained by the senior author. }\end{array}$ \\
\hline
\end{tabular}




\begin{tabular}{|c|c|}
\hline Study design: & Randomised, controlled trial. \\
\hline Outcome studied: & 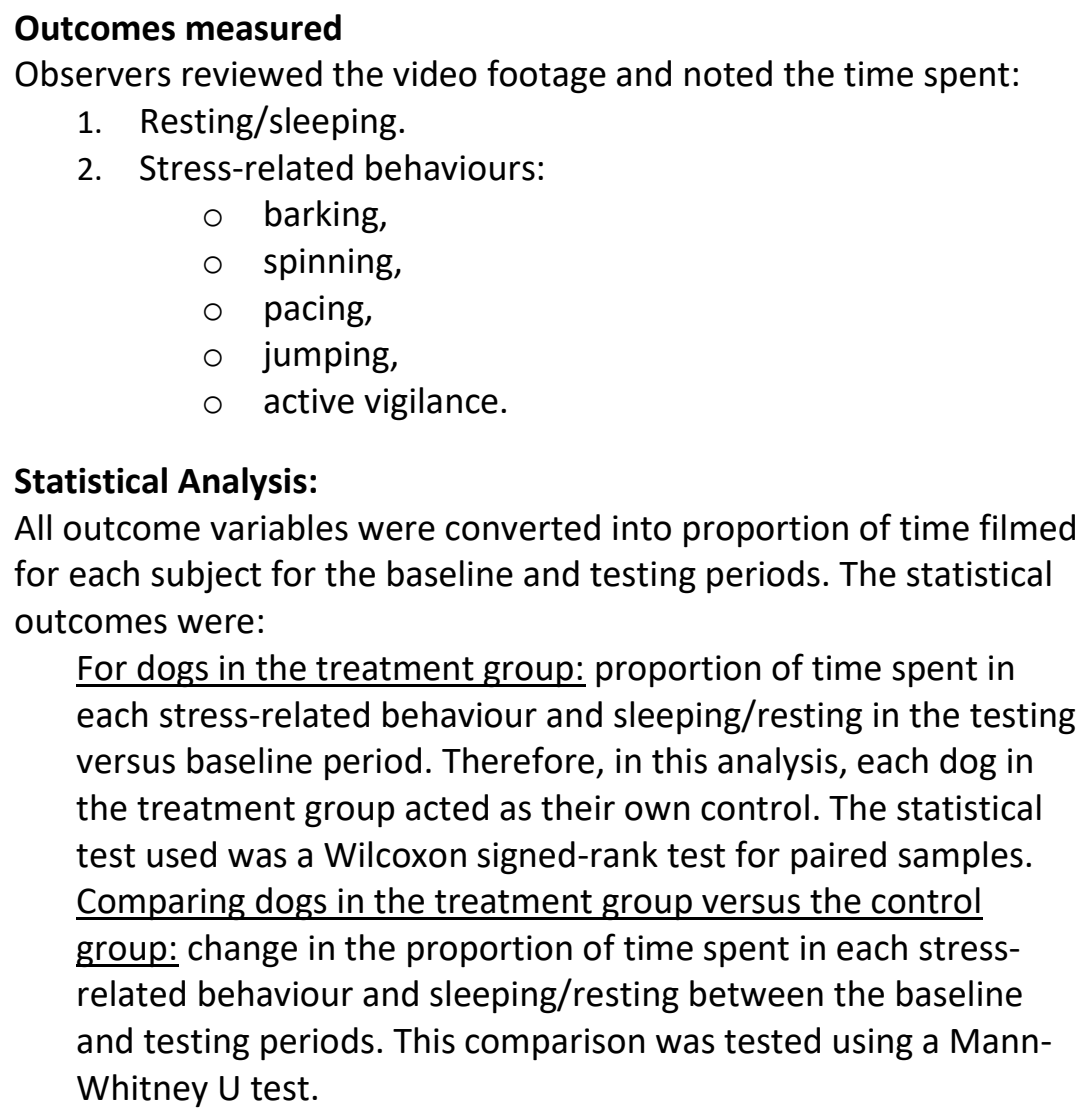 \\
\hline $\begin{array}{l}\text { Main findings: } \\
\text { (relevant to PICO question): }\end{array}$ & $\begin{array}{l}\text { - No significant difference was found in the proportion of time } \\
\text { dogs in the treatment group spent in any of the stress- } \\
\text { related behaviours or sleeping/resting in the baseline period } \\
\text { versus the testing period. } \\
\text { - No significant difference was found between the treatment } \\
\text { and control group for change in proportion of time dogs } \\
\text { spent in stress-related behaviours or sleeping/resting } \\
\text { between the baseline and testing periods. }\end{array}$ \\
\hline Limitations: & $\begin{array}{l}\text { - No sample size calculation. } \\
\text { - Small sample size (pilot study). } \\
\text { - } \quad \text { Technique of randomly selecting study participants from the } \\
\text { - eligible pool of dogs was not described. } \\
\text { - } \quad \text { Randomisation technique during allocation was not } \\
\text { described. } \\
\text { - } \quad \text { Nnclear if caregivers were blinded. } \\
\text { - Possibility for inter-observer bias. } \\
\text { - Subjects were still being used throughout the study period } \\
\quad \text { for normal teaching purposes which varied from dog to dog. } \\
\text { This may have been a source of confounding bias. }\end{array}$ \\
\hline
\end{tabular}




\begin{tabular}{|c|c|}
\hline Population: & $\begin{array}{l}\text { Shelter dogs undergoing orchiectomy or ovariohysterectomy } \\
\text { - Age: mean = } 29.1 \text { months, standard error }=3.1 \text { months. } \\
\text { - Breed: various. } \\
\text { - Gender: } 23 \text { males, } 23 \text { females. } \\
\text { - Length of stay: } \geq 20 \text { days. } \\
\text { Exclusions: } \\
\text { - Dogs }<6 \text { months or }>8 \text { years of age. } \\
\text { - Pregnant, lactating or pseudopregnant females with serum } \\
\text { - progesterone values between } 0-1 \mathrm{ng} / \mathrm{mL} \text {. } \\
\text { Dogs displaying behavioural signs of chronic stress such as } \\
\text { stereotypic behaviour (to minimise the confounding effect } \\
\text { of chronic confinement). }\end{array}$ \\
\hline Sample size: & 46 dogs. \\
\hline Intervention details: & $\begin{array}{l}\text { Dogs were randomly allocated into treatment and placebo groups: } \\
\text { - Treatment ( } \mathrm{n}=24) \text { : } 2 \% \text { DAP spray (Ceva Santé Animale). } \\
\text { All subjects were housed in an animal shelter in } 6 \mathrm{~m} 2 \text { pens with one } \\
\text { to two conspecifics. Subjects were placed into treatment or placebo } \\
\text { treated intensive care unit (ICU) cages for } 30 \text { minutes before and } \\
\text { after surgery. Each corner of an ICU cage was sprayed with } 10 \\
\text { pumps of the dispenser } 20 \text { minutes prior to use by subjects before } \\
\text { and after surgery. Cages were cleaned with detergent containing a } \\
\text { non-ionic fraction after each use. } \\
\text { Observation method: } \\
\text { Only the behavioural indicators of stress are relevant. Each subject's } \\
\text { behaviour was recorded at four timepoints, all on the same day: } \\
\text { T0: } 30-\text { minute recording of subject in shelter pens. } \\
\text { T1: recording of subject in pre-treated ICU cage } 30 \text { minutes prior } \\
\text { to surgery. } \\
\text { T2: recording of subject in pre-treated ICU cage for } 30 \text { minutes } \\
\text { once able to stand after surgery. } \\
\text { T3: } 30-\text { minute recording of subject once returned to animal } \\
\text { shelter. } \\
\text { Surgical procedure: } \\
\text { The following aspects were controlled between all subjects: } \\
\text { - Supervising surgeon. } \\
\text { - Anaesthetic drug protocol. } \\
\text { - Intravenous fluid rate (mL/kg/hr). } \\
\text { Post-surgical medications and dosages. }\end{array}$ \\
\hline Study design: & Randomised, controlled trial. \\
\hline Outcome studied: & $\begin{array}{l}\text { Indicators of stress were examined perioperatively: } \\
\text { - behavioural, } \\
\text { - neuroendocrine, } \\
\text { - immune, } \\
\text { - acute-phase responses. }\end{array}$ \\
\hline
\end{tabular}




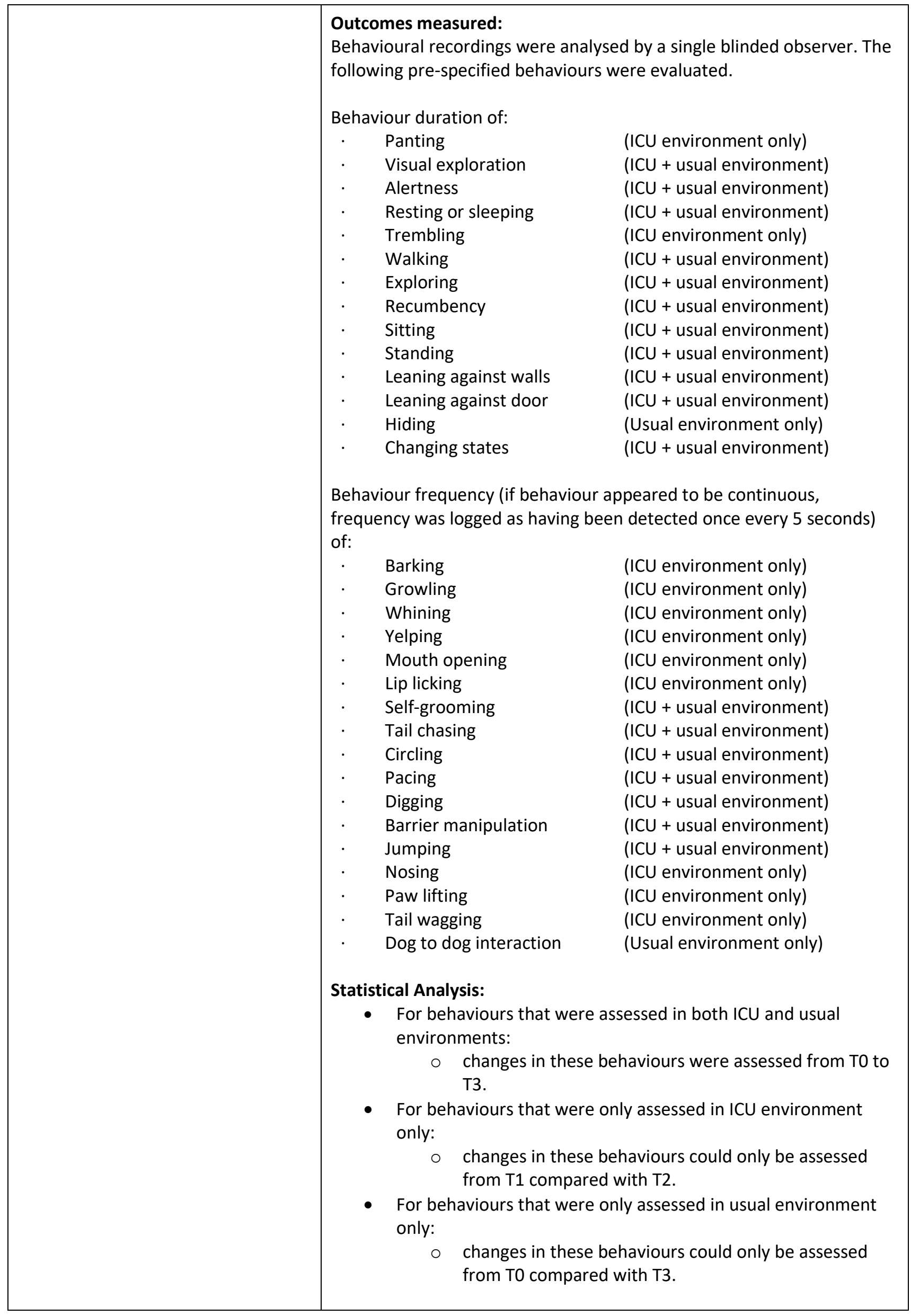




\begin{tabular}{|c|c|}
\hline & $\begin{array}{l}\text { The effect of DAP on change in behaviours over timepoints (T0, T1, } \\
T 2, T 3 \text { ) were analysed using a generalised linear model for repeated } \\
\text { measures. } \\
\text { The treatment and placebo groups were not significantly different } \\
\text { with respect to sex, age, or weight. Duration of surgery nor sedation } \\
\text { significantly differed between the two groups. }\end{array}$ \\
\hline $\begin{array}{l}\text { Main findings: } \\
\text { (relevant to PICO question): }\end{array}$ & 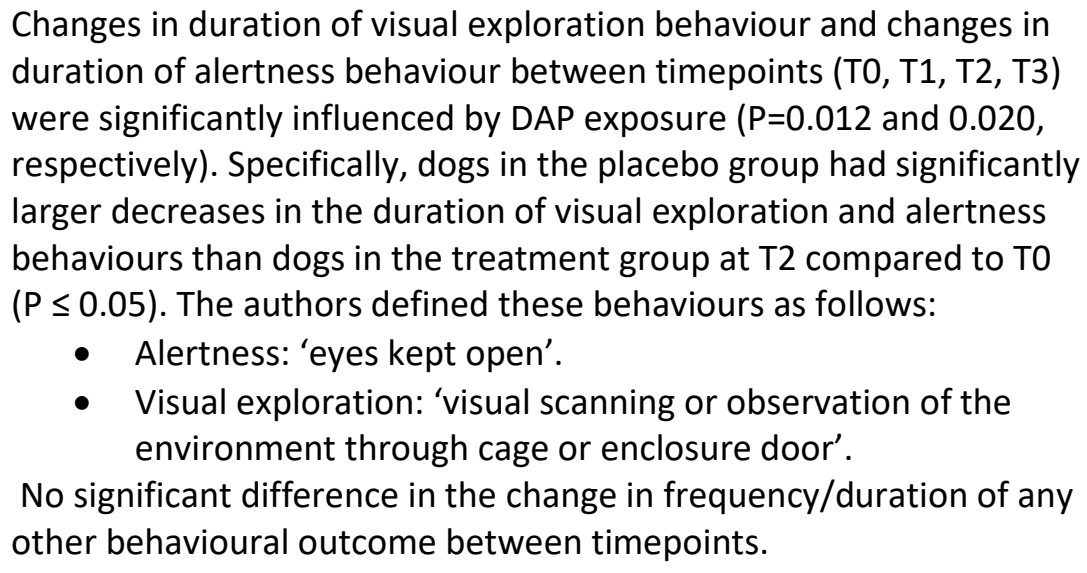 \\
\hline Limitations: & $\begin{array}{l}\text { - No sample size calculation, small sample size. } \\
\text { - } \quad \text { Random allocation sequence was created by the } \\
\text { manufacturer of the pheromone. Method of generating this } \\
\text { sequence was not described. } \\
\text { - It was not possible to log all behaviours at both locations } \\
\text { (animal shelter versus ICU cage) due to differences in } \\
\text { housing (individual vs in groups), accessibility of hiding } \\
\text { places and distance of the video camera from subjects. } \\
\text { - Interaction of subjects with other conspecifics in the animal } \\
\text { shelter could be a source of bias that may alter results in an } \\
\text { unpredictable direction. } \\
\text { The number of other conspecifics in the same pen was not } \\
\text { controlled between subjects. The personality of, and } \\
\text { interactions with these other dogs was problematic to } \\
\text { control. } \\
\text { Each surgery was assisted by different veterinary students. } \\
\text { The role and extent of student involvement was not defined, } \\
\text { and this may or may not create bias due to differences in } \\
\text { caregiving to subjects. }\end{array}$ \\
\hline
\end{tabular}

Kim et al. (2010)

Population: Dogs hospitalised for $>4$ days at Lee Jong Kyung Veterinary Clinic, South Korea.

- Age: mean $=5.6$ years, range $=1-17$ years .

- Neutering status: $23.3 \%$ neutered, $76.7 \%$ intact.

- Breed: various breeds.

- Gender: 23 females, 20 males

- Mix of disease diagnoses: renal dysplasia, meningoencephalitis of unknown origin, glaucoma, mitral valve insufficiency, oesophageal foreign body, intervertebral disc disease, pancreatitis, mammary gland adenocarcinoma, 


\begin{tabular}{|c|c|}
\hline & $\begin{array}{l}\text { inflammatory mammary gland carcinoma, haemophthalmia, } \\
\text { oestrogen-toxicity and anaemia, chronic renal failure, } \\
\text { fibrosarcoma, lymphoma and hemivertebra. } \\
\text { The following dogs were excluded from participation: those with } \\
\text { abnormal cognitive conditions, to be anaesthetised for surgery, or } \\
\text { being treated with large amounts of analgesics or psychotropic } \\
\text { drugs. }\end{array}$ \\
\hline Sample size: & 43 dogs. \\
\hline Intervention details: & 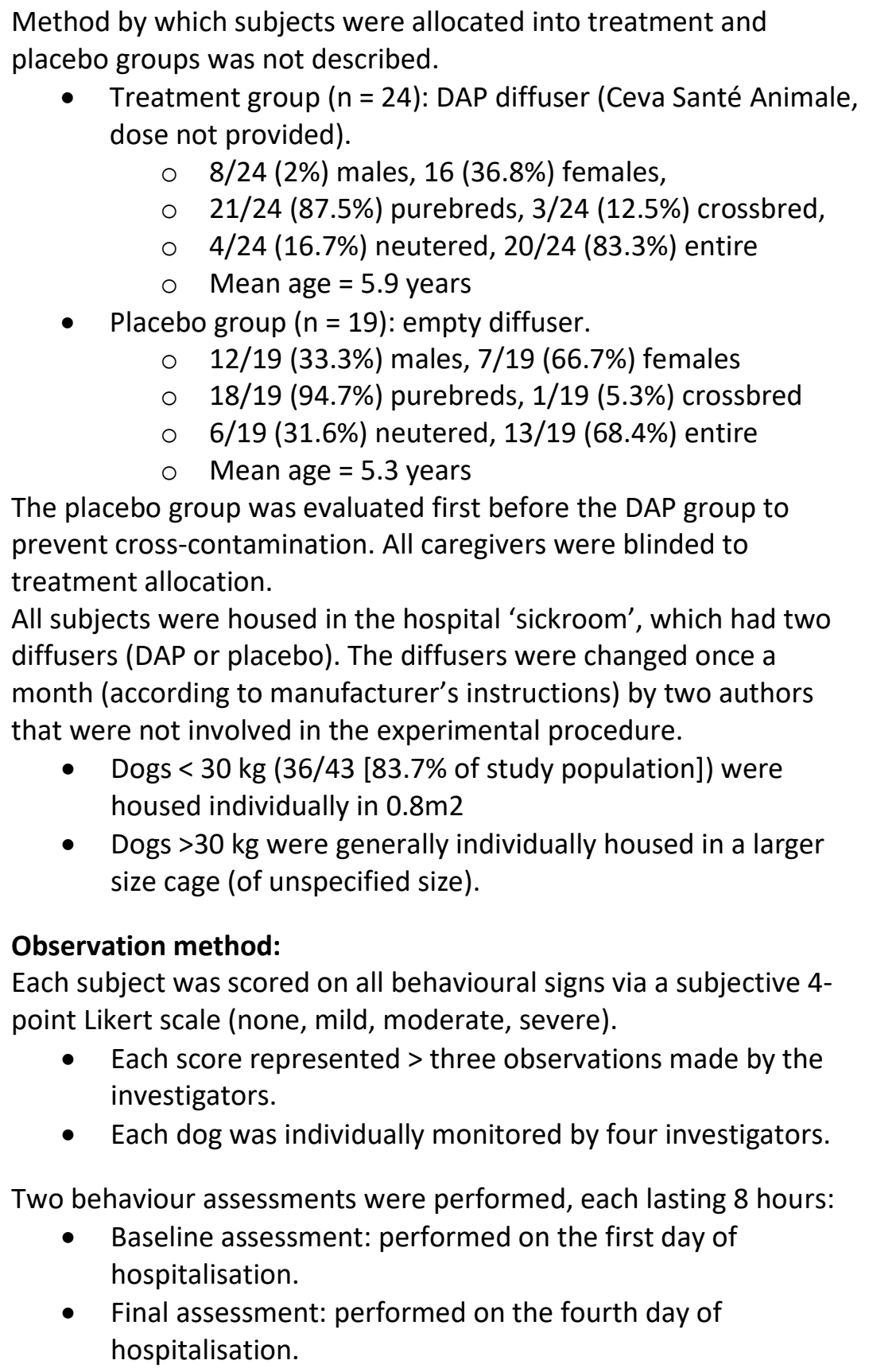 \\
\hline Study design: & Controlled trial. Unclear whether this trial was randomised. \\
\hline Outcome studied: & $\begin{array}{l}\text { Outcomes measured: } \\
\text { Severity or frequency of ten separation-related behavioural signs: } \\
\text { - destructiveness, } \\
\text { - vocalisation, }\end{array}$ \\
\hline
\end{tabular}




\begin{tabular}{|c|c|}
\hline & $\begin{array}{l}\text { - } \text { elimination, } \\
\text { - } \text { excessive licking, } \\
\text { - } \text { anorexia, } \\
\text { - } \text { hypersalincestinalion, } \\
\text { - } \text { trembling, } \\
\text { - pacing. } \\
\text { Statistical Analysis: } \\
\text { The mean ranks for each separation-related behaviour sign were } \\
\text { compared between the placebo and treatment group using a Mann- } \\
\text { Whitney U-test. } \\
\text { 'Change in behavioural state' over these } 4 \text { days for was calculated for } \\
\text { each behaviour factor by subtracting the final score from the baseline } \\
\text { score. No statistical test was performed to investigate differences in } \\
\text { change of behavioural state between the placebo and treatment group. } \\
\text { A Pearson's Chi Square test was used to investigate the influence of age } \\
\text { and sex on the efficacy of DAP in placebo and treatment groups. }\end{array}$ \\
\hline $\begin{array}{l}\text { Main findings: } \\
\text { (relevant to PICO question): }\end{array}$ & $\begin{array}{l}\text { 'Mean ranks for behavioural states' } \\
\text { - Elimination ( } P=0.038) \text {, excessive licking }(P=0.005) \text { and pacing } \\
(P=0.017) \text { was significantly ameliorated after treatment when } \\
\text { compared to placebo. } \\
\circ \quad \text { A decrease in elimination could reflect a lesser } \\
\text { activation of the fight or flight response after DAP } \\
\text { administration. } \\
\text { 'Change in behavioural states' } \\
\text { 'Change in behavioural state' was calculated for each behaviour } \\
\text { factor by subtracting the final score from the baseline score. No } \\
\text { formal statistical analysis was performed for this outcome } \\
\text { variable. The authors noted descriptively that } 9 / 10 \text { separation- } \\
\text { related behaviours were observed to be improved in the } \\
\text { treatment group when compared to placebo (except for } \\
\text { 'gastrointestinal problems'). }\end{array}$ \\
\hline Limitations: & $\begin{array}{l}\text { - Small sample size. } \\
\text { - } \quad \text { Po calculation of sample size. } \\
\text { pain, cage confinement and noise from other dogs in the } \\
\text { hospital } \\
\text { - Unbalanced demographic factors between treatment and } \\
\text { placebo groups which may be confounding. } \\
\text { - Method of allocating study population into treatment vs } \\
\text { placebo groups not described. } \\
\text { - Intrinsic differences in caregiving between subjects (since each } \\
\text { have different medical diagnoses). } \\
\text { It is unclear how long the diffuser was installed in the hospital } \\
\text { 'sickroom' prior to the subjects being exposed. The } \\
\text { manufacturer recommends allowing at least } 24 \text { hours for the } \\
\text { pheromone to diffuse into a room before exposure to subjects } \\
\text { (Ceva Animal Health Pty Ltd, n.d.). } \\
\text { - The description for assessment of behaviour state in the } \\
\text { methods section is vague: }\end{array}$ \\
\hline
\end{tabular}




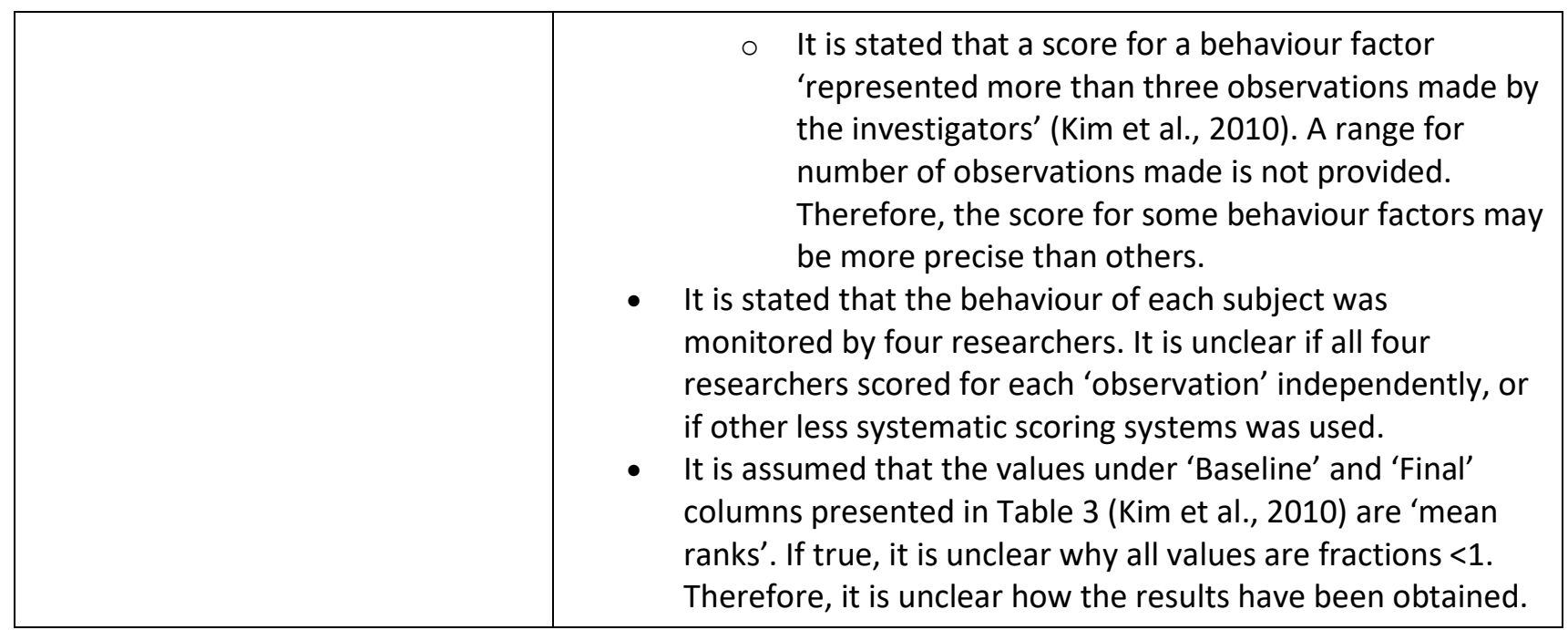

\section{Appraisal, application and reflection}

Anxiety can be defined as anticipation of future danger, whether real or imagined, often despite the absence of any specific object of threat (Tiira et al., 2016). Dogs suffering from anxiety can have a negative emotional response to many innocuous stimuli in their environment and those experiencing a continual state of anxiety have compromised welfare (Salonen et al., 2020; and Beata et al., 2007). Canine anxiety can strain the humananimal bond and is a major reason for animal surrender (Miller et al., 1996). Dog Appeasing Pheromone (DAP), a synthetic version of Canine Appeasing Pheromone marketed as Adaptil ${ }^{\circledR}$ (Ceva Santé Animale) is a popular adjunctive therapy for canine anxiety. Endogenous canine appeasing pheromone is secreted by the bitch shortly after parturition and is detected by the vomeronasal organ (Pageat \& Gaultier, 2003). Interestingly, it is reported to have calming effects on both young and adult dogs (Pageat \& Gaultier, 2003).

Frank et al. (2010) conducted a systematic review of prospective studies published between January 1998 and December 2008 to assess the evidence for treating undesirable canine behaviours with DAP. This systematic review determined that six studies yielded insufficient evidence for using DAP to treat undesirable behaviours, whilst the seventh provided sufficient evidence that DAP collar helped reduce fear or anxiety during training in puppies 12-15 weeks of age. However, several relevant studies have since been published and to the authors' knowledge, these have not been appraised in a systematic manner. This Knowledge Summary was limited to randomised and non-randomised controlled trials as these study designs provide the most reliable evidence for assessing efficacy of interventions (O'Connor et al., 2014).

This PICO question was focused on dogs older than 6 months of age because although canine appeasing pheromone is endogenously released by a lactating bitch for puppies, synthetic DAP is still reportedly indicated for use in adolescent and adult dogs. From a behavioural development perspective, the juvenile period ends at 6 months of age, and this usually also coincides with sexual maturity (Scott \& Fuller, 1965). Additionally, the dog has already surpassed both the early and late socialisation period by this age (Dietz et al., 2018).

Three studies investigated DAP spray, but the method of application differed. One study applied the spray on a bandana (Amaya et al., 2020) whereas the other two applied it to the corners of the kennel (Hermiston et al., 2018) or cage floor (Siracusa et al., 2010). The quantity of DAP used varied from 3-10 pumps for each treatment. Concentration of DAP used also varied between unreported (Hermiston et al., 2018), to $2 \%$ (Siracusa et al., 2010) to $15.72 \mathrm{mg} / \mathrm{ml}$ (Amaya et al., 2020). The findings between these three studies were inconsistent. In the study by Amaya et al. (2020), a short length of each observation and large gaps between each observation resulted in inadequate data collection to statistically analyse licking nose/lip behaviours which are well-known displacement behaviours (Lund \& Jørgensen, 1999). However, DAP-treated dogs spent more time lying down as well as less time panting, vocalising and moving the tail. In combination, these behaviours are suggestive of increased relaxation in this study. In contrast, Siracusa et al. (2010) found that 
DAP spray increased the duration of alertness ('eyes kept open') and visual exploration, which are behaviours classically associated with increased arousal rather than relaxation (Hammerle et al., 2015; and Overall, 2013). The significance of this finding is ambiguous and might simply reflect exploratory behaviour secondary to the presence of DAP in the environment. The third study by Hermiston et al. (2018) found that exposure to DAP was associated with reduced barking intensity only. This finding may or may not reflect a change in the animal's emotional state and is difficult to interpret as all other indicators of stress were not significantly affected. In addition, there are many causes of barking and this behaviour is not necessarily specific to anxiety, stress or fear (Hermiston et al., 2018). The discrepancy in results and methodology between these three studies is problematic, but the design of Siracusa et al. (2010) was least prone to bias whereas Hermiston et al. (2018) was most prone to bias. The reasons for this have already been described in 'The Evidence' section of this Knowledge Summary.

For the three studies that evaluated DAP collar, only one (Broach \& Dunham, 2016) reported the concentration of DAP impregnated within the collar. Landsberg et al. (2015) was the only study that had significant findings $(P<0.05)$. In this trial, DAP collar was reported to significantly reduce the frequency and intensity of 'active' behavioural signs of fear and anxiety in middle-aged to geriatric Beagles during and immediately after stimulation with thunderstorm audio. This study carries moderate evidence but was funded by the manufacturer of the product and at least one statistician involved was also employed by the manufacturer at the time. As there was no formal conflict of interest declaration, these are perceived conflicts of interest that should be noted. Allocation of subjects into treatment and placebo groups was performed by systematic alternation rather than true randomisation, which could lead to unequal distribution of confounding factors between groups. If any allocation was unmasked, then internal validity of the study would also be compromised (Berger \& Grant, 2014). The study by Broach \& Dunham (2016) found no significant effects of DAP vs placebo collar in any behaviour category including 'distress' and 'aggression/affability' (although not all canine aggression is necessarily attributed to anxiety (Sueda \& Malamed, 2014)). In this study, it is assumed that the outcome 'mean score' for each behaviour category was an average of all three behavioural assessments as this was not clarified in the publication. However, including the results from all three behavioural assessments in the calculation of 'mean score' for a given behaviour category would potentially obscure any true differences between the treatment and control groups. This is because subjects did not wear collars in the first (baseline) behavioural assessment and had stopped wearing collars for 1 week by the time of the last (third) behavioural assessment. Furthermore, the outcome 'change in score' for each behaviour category was calculated by subtracting the final behavioural assessment score from the initial behavioural assessment score. Unless DAP collar has a residual effect of $\geq 1$ week, this approach would clearly also be unlikely to detect any treatment effects.

The two studies that investigated DAP diffuser (Taylor et al., 2020; and Kim et al., 2010) yielded inconsistent findings and only one reported the concentration of DAP (Taylor et al., 2020). In both studies, it was unclear how long the DAP diffuser was switched on for before subjects were exposed. The manufacturer recommends allowing at least 24 hours for the pheromone to diffuse into a room before exposure to subjects (Ceva Animal Health Pty Ltd, n.d.). The first study found that a DAP diffuser did not influence behaviours (some of which were considered anxiety-related) in dogs separated from their owners in a laboratory environment (Taylor et al., 2020). The trial was placebo-controlled and double-blinded, but order and time effects may have biased the results. The effect size may also have been reduced due to sensitisation from learnt association of the study site with owner separation. Furthermore, results for yawning and lip-licking (which may be considered anxiety-related behaviours [Hammerle et al., 2015]) were not described. The second study (Kim et al., 2010) found that the intervention significantly $(P<0.05)$ ameliorated 'excessive licking' and 'pacing' behaviours. Excessive licking and pacing are commonly associated with stress and anxiety (Hammerle et al., 2015), so this finding could reflect a beneficial treatment effect. However, there were many potential confounders including level of pain, noise of other dogs and medical diagnoses that were not controlled for. Furthermore, subjects were hospitalised for a multitude of disease diagnoses that necessitated intrinsic differences in caregiving. In addition, the allocation of subjects was unclear, and the description of methodology and statistical analysis was ambiguous. As a result, it was unclear how some values presented in the results section were obtained (see 'Summary of Evidence' section). 
Overall, no study reported a formal sample size calculation. Failure to perform this calculation could reduce the power of statistical analyses if sample sizes were too small. However, it is likely that sample size calculation is difficult for the outcome variables in behavioural studies (Taborsky, 2010). One study (Broach \& Dunham, 2016) stated that a sample size calculation was not performed due to a lack of baseline data.

In this Knowledge Summary, all studies except for two (Taylor et al., 2020; and Siracusa et al., 2010) either lacked or did not report a statistical analysis of intra and/or inter-observer agreement for behavioural observations. These metrics are important to reveal any potential impact of rater scoring drift and observer bias (Girard \& Cohn, 2016). This is especially important in behaviour studies where outcome variables are often subjective. The importance and prevalence of this issue in animal behaviour research have been discussed in detail in the literature (Burghardt et al., 2012; and Kaufman \& Rosenthal, 2009).

The systematic review by Frank et al. (2010) cites some flaws in the design validity of reviewed articles published between January 1998 and December 2008. Some limitations included the introduction of confounding bias from concurrent treatments or environmental changes, and failure of intention-to-treat analysis when there was loss to follow up. This is important because failure of either can introduce selection bias and/or increase the likelihood of non-comparability between treatment groups with respect to potential confounders (O'Connor et al., 2014; and Fives et al., 2013). In this Knowledge Summary, the relevant controlled trials published between 2009 and June 2021 continue to be affected by similar limitations to those that were reviewed by Frank et al. (2010). All four randomised controlled trials included in this Knowledge Summary still failed to report the method of generating randomisation sequences (Amaya et al., 2020; Broach \& Dunham, 2016; Grigg \& Piehler, 2015; and Siracusa et al., 2010) and three failed to report concealment of allocation into treatment groups (Amaya et al., 2020; Broach \& Dunham, 2016; and Grigg \& Piehler, 2015). Additionally, blinding of assessors and/or caregivers in some of the studies appraised in this Knowledge Summary was either incomplete (Hermiston et al., 2018), or unclear (Amaya et al., 2020; Grigg \& Piehler, 2015; and Siracusa et al., 2010).

Overall, the level of evidence from controlled trials published since the systematic review by Frank et al. (2010) remains of low quality and/or with moderate risk of bias. This was true for all studies regardless of their findings. There were inconsistencies in the effects of DAP on behavioural outcomes; flaws in experimental designs; differences in the concentration of DAP between and within formulations; heterogeneity in methodology between studies; and potential conflicts of interest sometimes declared or undeclared.

There are several limitations to this knowledge summary. Firstly, reviewing a dog's body language is inevitably subjective and context-specific (Paul et al., 2005). Measures of behavioural signs between observers are not always reliable and this is a limitation of drawing conclusions from multiple studies (Bradshaw \& Casey, 2007; and Wemelsfelder, 2001). Secondly, veterinary practitioners should be aware that a reduction in non-specific stress behaviours does not necessarily equate to successful treatment. This is because the behaviour displayed by an animal is only a surrogate measure of anxiety and is not a direct reflection of its emotional state (Mills, 2017). Thirdly, some behaviours occur due to a variety of motivational reasons (Paul et al., 2005) and aetiologies. These factors can result in individual variation between subjects and are problematic to control in experimental designs of behaviour studies. Therefore, control to limit variability between treatments, the requirement of a placebo, and well-defined hypotheses that can facilitate calculation of adequate sample sizes for each treatment group are paramount for study implementation. Additionally, concurrent interpretation of behaviour with physiological stress parameters may provide a more accurate assessment for canine anxiety (Taylor et al., 2020).Fourthly, this Knowledge Summary has highlighted the inconsistency in findings between eligible studies. This is likely at least partially due to the broad PICO question resulting in the inclusion of many studies with heterogenous study populations that assessed a breadth of indications. Fifthly, other study designs such as well-designed observational studies may have contributed more evidence for the PICO question but were excluded from appraisal in this Knowledge Summary. Lastly, this study focused on the population of patients older than 6 months of age but learning and occasionally cognitive development continues to progress beyond this. The timing of behavioural maturity in domestic dogs is a complicated and under-researched topic (Harvey, 2021). The possible effect of ongoing cognitive development and behavioural immaturity on an individual dog's emotional state and behaviour after being exposed to DAP is unclear. 
In conclusion, there is a continued knowledge gap concerning the effectiveness of DAP in treating non-specific stress behaviours associated with anxiety. Testing within the home environment should be a future consideration for further research, although controlling for differences in the home environment and caregiving would be problematic.

\section{Methodology Section}

\section{Search Strategy}

Databases searched and dates CAB Abstracts via Web of Science (2009-2021)

covered: Web of Science Core Collections (2009-2021)

Medline via OvidSP (2009-2021)

Scopus (2009-2021)

Search terms: This Knowledge Summary aims to appraise newer publications that were not included in the systemic review by Frank et al. (2010). Frank et al. (2010) reviewed relevant prospective studies published between January 1998 and December 2008. Therefore, all searches for this Knowledge Summary were limited to papers published during, or after the year 2009.

\section{CAB Abstracts}

$\mathrm{TS}=$ (pheromone* OR "canine appeasing pheromone" OR "dog appeasing pheromone" OR "DAP" OR adaptil OR apasine OR pheromonotherap* OR pheromonatherap* OR "pheromone therapy" OR "pheromone based therapy") AND TS=(canine* or dog or dogs or bitches or bitch or canis or canids or canid or canidae)

**TS = searches title, abstract, author keywords, and Keywords Plus fields.

Web of Science

$\mathrm{TS}=$ (pheromone* OR "canine appeasing pheromone" OR "dog appeasing pheromone" OR "DAP" OR adaptil OR apasine OR pheromonotherap* OR pheromonatherap* OR "pheromone therapy" OR "pheromone based therapy") AND TS=(canine* or dog or dogs or bitches or bitch or canis or canids or canid or canidae)

**TS = searches title, abstract, author keywords, and Keywords Plus fields.

Medline

1. (pheromone* or "canine appeasing pheromone" or "dog appeasing pheromone" or "DAP" or adaptil or apasine or pheromonotherap* or pheromonatherap* or "pheromone therapy" or "pheromone based therapy").mp.

2. (canine* or dog or dogs or bitches or bitch or canis or canids or canid or canidae).mp.

3. 1 and 2

4. Limit 3 to $y r=" 2009-2021 "$

**.m.p. searches abstract, floating sub-heading word, keyword heading word, name of substance word, organism supplementary 


\begin{tabular}{|c|c|}
\hline & $\begin{array}{l}\text { concept word, original title, protocol supplementary word, rare } \\
\text { disease supplementary concept word, subject heading word, } \\
\text { synonyms, title, unique identifier. } \\
\text { Scopus } \\
\text { ( TITLE-ABS-KEY ( pheromone* OR "canine appeasing pheromone" } \\
\text { OR "dog appeasing pheromone" OR adaptil OR apasine OR } \\
\text { pheromonotherap* OR pheromonatherap* OR "pheromone } \\
\text { therapy") ) AND ( TITLE-ABS-KEY ( canine* OR dog OR dogs OR } \\
\text { bitches OR bitch OR canis OR canid OR canidae OR canids )) } \\
\text { AND ( LIMIT-TO ( PUBYEAR, 2021) OR LIMIT-TO ( PUBYEAR, } 2020 \\
\text { ) OR LIMIT-TO (PUBYEAR, 2019) OR LIMIT-TO ( PUBYEAR, } 2018 \\
\text { ) OR LIMIT-TO ( PUBYEAR, 2017) ) OR LIMIT-TO ( PUBYEAR, } 2016 \\
\text { ) OR LIMIT-TO (PUBYEAR, 2015) OR LIMIT-TO ( PUBYEAR, } 2014 \\
\text { ) OR LIMIT-TO ( PUBYEAR, 2013) OR LIMIT-TO ( PUBYEAR, } 2012 \\
\text { ) OR LIMIT-TO ( PUBYEAR, 2011) OR LIMIT-TO ( PUBYEAR, } 2010 \\
\text { ) OR LIMIT-TO (PUBYEAR, 2009)) } \\
\text { ** TITLE-ABS-KEY searches document titles, abstracts and keywords. }\end{array}$ \\
\hline Dates searches performed: & 24 Jun 2021 \\
\hline \multicolumn{2}{|l|}{ Exclusion / Inclusion Criteria } \\
\hline Exclusion: & $\begin{array}{l}\text { - Non-English language publications. } \\
\text { - Study designs that are not controlled clinical trials. } \\
\text { - Articles not relevant to the PICO question. }\end{array}$ \\
\hline Inclusion: & $\begin{array}{l}\text { - Any controlled trial (randomised or non-randomised) } \\
\text { relevant to the PICO question, using only DAP as the } \\
\text { intervention. }\end{array}$ \\
\hline
\end{tabular}

\begin{tabular}{|c|c|c|c|c|c|c|}
\hline \multicolumn{7}{|c|}{ Search Outcome } \\
\hline Database & $\begin{array}{c}\text { Number } \\
\text { of } \\
\text { results }\end{array}$ & $\begin{array}{l}\text { Excluded - } \\
\text { Not English } \\
\text { language }\end{array}$ & $\begin{array}{l}\text { Excluded - } \\
\text { Irrelevant to } \\
\text { PICO question }\end{array}$ & $\begin{array}{c}\text { Excluded - Not a } \\
\text { controlled trial }\end{array}$ & $\begin{array}{l}\text { Excluded - } \\
\text { Duplicates }\end{array}$ & $\begin{array}{c}\text { Total } \\
\text { relevant } \\
\text { papers }\end{array}$ \\
\hline $\begin{array}{l}\mathrm{CAB} \\
\text { Abstracts }\end{array}$ & 207 & 32 & 113 & 54 & 8 & 0 \\
\hline $\begin{array}{l}\text { Web of } \\
\text { Science }\end{array}$ & 278 & 17 & 238 & 16 & 7 & 0 \\
\hline Medline & 139 & 2 & 129 & 3 & 5 & 0 \\
\hline Scopus & 135 & 4 & 104 & 19 & $\mathrm{~N} / \mathrm{A}$ & 8 \\
\hline \multicolumn{6}{|c|}{ Total relevant papers when duplicates removed } & 8 \\
\hline
\end{tabular}




\section{CONFLICT OF INTEREST}

The authors declare no conflicts of interest.

The authors would like to acknowledge Sydney School of Veterinary Science colleague Dr Anne Fawcett for her thoughtful revision of this manuscript.

\section{REFERENCES}

1. Amaya, V., Paterson, M. B. A. \& Phillips, C. J. C. (2020). Effects of Olfactory and Auditory Enrichment on the Behaviour of Shelter Dogs. Animals. 10(4), 581. DOI: https://doi.org/10.3390/ani10040581

2. Beata, C., Beaumont-Graff, E., Diaz, C., Marion, M., Massal, N., Marlois, N., Muller, G. \& Lefranc, C. (2007). Effects of alpha-casozepine (Zylkene) versus selegiline hydrochloride (Selgian, Anipryl) on anxiety disorders in dogs. Journal of Veterinary Behavior. 2(5), 175-183.

DOI: https://doi.org/10.1016/j.jveb.2007.08.001

3. Beerda, B., Schilder, M. B. H., van Hooff, J. A. R. A. M., de Vries, H. W. \& Mol, J. A. (1998). Behavioural, saliva cortisol and heart rate responses to different types of stimuli in dogs. Applied Animal Behaviour Science. 58(3-4), 365-381. DOI: https://doi.org/10.1016/s0168-1591(97)00145-7

4. Berger, V. W. \& Grant, W. (2014). A review of randomization methods in clinical trials. In: W.R. Young \& D.-G.D. Chen, eds., Clinical Trial Biostatistics and Biopharmaceutical Applications, $1^{\text {st }}$ ed. London: CRC Press LLC, 41-54.

5. Bradshaw, J. W. S. \& Casey, R. A. (2007). Anthropomorphism and anthropocentrism as influences in the quality of life of companion animals. Animal Welfare. 16(S1), 149-154. [online] Available from: https://www.ingentaconnect.com/content/ufaw/aw/2007/00000016/a00102s1/art00022 [Acce ssed 07 Aug 2020].

6. Broach, D. \& Dunham, A. E. (2016). Evaluation of a pheromone collar on canine behaviors during transition from foster homes to a training kennel in juvenile Military Working Dogs. Journal of Veterinary Behavior. 14(July-August), 41-51. DOI: https://doi.org/10.1016/j.jveb.2016.05.001

7. Burghardt, G. M., Bartmess-LeVasseur, J. N., Browning, S. A., Morrison, K. E., Stec, C. L., Zachau, C. E. \& Freeberg, T. M. (2012). Perspectives-minimizing observer bias in behavioral studies: a review and recommendations. Ethology. 118(6), 511-517. DOI: https://doi.org/10.1111/j.1439-0310.2012.02040.x

8. Ceva Animal Health Pty Ltd. (n.d.). FAQ. Available at: https://www.adaptil.com/au/Products/FAQ [Accessed 07 Sep 2020].

9. Dietz, L., Arnold, A.-M. K., Goerlich-Jansson, V. C. \& Vinke, C. M. (2018). The importance of early life experiences for the development of behavioural disorders in domestic dogs. Behaviour. 155(2-3), 83114. DOI: https://doi.org/10.1163/1568539X-00003486

10. Fives, A., Rusell, D. W., Kearns, N., Lyons, R., Eaton, P., Canavan, J., Devaney, C. \& O'Brien, A. (2013). The role of random allocation in randomized controlled trials: distinguishing selection bias from baseline imbalance. Journal of MultiDisciplinary Evaluation. 9(20), 33-42. [online] Available from: https://journals.sfu.ca/jmde/index.php/jmde 1/article/view/371 [Accessed 17 Aug 2020].

11. Frank, D., Beauchamp, G. \& Palestrini, C. (2010). Systematic review of the use of pheromones for treatment of undesirable behavior in cats and dogs. J Am Vet Med Assoc. 236(12), 1308-1316. DOI: https://doi.org/10.2460/javma.236.12.1308

12. Girard, J. M. \& Cohn, J. F. (2016). A Primer on Observational Measurement. Assessment. 23(4), 404413. DOI: https://dx.doi.org/10.1177\%2F1073191116635807

13. Grigg, E. K. \& Piehler, M. (2015). Influence of dog appeasing pheromone (DAP) on dogs housed in a long-term kennelling facility. Vet Rec Open. 2(1), e000098. DOI: http://dx.doi.org/10.1136/vetreco2014-000098

14. Hammerle, M., Horst, C., Levine, E., Overall, K., Radosta, L., Rafter-Ritchie, M. \& Yin, S. (2015). 2015 AAHA Canine and Feline Behavior Management Guidelines. J Am Anim Hosp Assoc. 51(4), 205-221. DOI: https://doi.org/10.5326/JAAHA-MS-6527 
15. Harvey, N. D. (2021). How Old Is My Dog? Identification of Rational Age Groupings in Pet Dogs Based Upon Normative Age-Linked Processes. Front Vet Sci. 8(321), 643085.

DOI: https://doi.org/10.3389/fvets.2021.643085

16. Hermiston, C., Montrose, V. T. \& Taylor, S. (2018). The effects of dog-appeasing pheromone spray upon canine vocalizations and stress-related behaviors in a rescue shelter. Journal of Veterinary Behavior. 26(July-August), 11-16. DOI: https://doi.org/10.1016/i.jveb.2018.03.013

17. Kaufman, A. B. \& Rosenthal, R. (2009). Can you believe my eyes? The importance of interobserver reliability statistics in observations of animal behaviour. Animal Behaviour. 78(6), 1487-1491. DOI: https://psycnet.apa.org/doi/10.1016/i.anbehav.2009.09.014

18. Kim, Y. M., Lee, J. K., Abd el-aty, A. M., Hwang, S. H., Lee, J. H. \& Lee, S. M. (2010). Efficacy of dogappeasing pheromone (DAP) for ameliorating separation-related behavioral signs in hospitalized dogs. Can Vet J. 51(4), 380-384. [online] Available from: https://www.ncbi.nlm.nih.gov/pubmed/20592826 [Accessed 24 June 2021].

19. Landsberg, G. M., Beck, A., Lopez, A., Deniaud, M., Araujo, J. A. \& Milgram, N. W. (2015). Dogappeasing pheromone collars reduce sound-induced fear and anxiety in beagle dogs: a placebocontrolled study. Vet Rec. 177(10), 260. DOI: http://dx.doi.org/10.1136/vr.103172

20. Lund, J. D. \& Jørgensen, M. C. (1999). Behaviour patterns and time course of activity in dogs with separation problems. Applied Animal Behaviour Science. 63(3), 219-236. DOI: https://doi.org/10.1016/S0168-1591(99)00011-8

21. Miller, D. D., Staats, S. R., Partlo, C. \& Rada, K. (1996). Factors associated with the decision to surrender a pet to an animal shelter. J Am Vet Med Assoc. 209(4), 738-742. [online] Available from: https://www.scopus.com/inward/record.uri?eid=2-s2.0$0030586603 \&$ partnerID=40\&md5=d7816937c703fcb27da23906255e3d12 [Accessed 08 Aug 2020].

22. Mills, D. S. (2017). Perspectives on assessing the emotional behavior of animals with behavior problems. Current Opinion in Behavioral Sciences. 16(August), 66-72.

DOI: https://doi.org/10.1016/i.cobeha.2017.04.002

23. O'Connor, A. M., Sargeant, J. M. \& Wang, C. (2014). Conducting systematic reviews of intervention questions III: Synthesizing data from intervention studies using meta-analysis. Zoonoses Public Health. 61(S1), 52-63. DOI: https://doi.org/10.1111/zph.12123

24. Overall, K. (2013). Manual of Clinical Behavioral Medicine for Dogs and Cats-E-Book. Elsevier Health Sciences. [online] Available from: https://ebookcentral-proquestcom.ezproxy.library.sydney.edu.au/lib/usyd/detail.action?doclD=1431145 [Accessed $30 \mathrm{Jul}$ 2020].

25. Pageat, P. \& Gaultier, E. (2003). Current research in canine and feline pheromones. Vet Clin North Am Small Anim Pract. 33(2), 187-211. DOI: https://doi.org/10.1016/S0195-5616(02)00128-6

26. Paul, E. S., Harding, E. J. \& Mendl, M. (2005). Measuring emotional processes in animals: the utility of a cognitive approach. Neurosci Biobehav Rev. 29(3), 469-91.

DOI: https://doi.org/10.1016/i.neubiorev.2005.01.002

27. Pierotti, P. (2016). Clinical applications of pheromones in dogs. Dog Behavior. 2(2), 20-26. DOI: https://doi.org/10.4454/db.v2i2.32

28. Prior, M. R. \& Mills, D. S. (2020). Cats vs. Dogs: The Efficacy of Feliway Friends(TM) and Adaptil(TM) Products in Multispecies Homes. Front Vet Sci. 7(399).

DOI: https://dx.doi.org/10.3389/fvets.2020.00399

29. Protopopova, A. (2016). Effects of sheltering on physiology, immune function, behavior, and the welfare of dogs. Physiol Behav. 159(15 May 2016), 95-103.

DOI: https://doi.org/10.1016/i.physbeh.2016.03.020

30. Salonen, M., Sulkama, S., Mikkola, S., Puurunen, J., Hakanen, E., Tiira, K., Araujo, C. \& Lohi, H. (2020). Prevalence, comorbidity, and breed differences in canine anxiety in 13,700 Finnish pet dogs. Sci Rep. 10(1), 2962. DOI: https://doi.org/10.1038/s41598-020-59837-z

31. Scott, J. \& Fuller, J. (1965). Genetics and social behavior of the dog. University of Chicago Press. Chicago. 
32. Siracusa, C., Manteca, X., Cuenca, R., del Mar Alcala, M., Alba, A., Lavin, S. \& Pastor, J. (2010). Effect of a synthetic appeasing pheromone on behavioral, neuroendocrine, immune, and acute-phase perioperative stress responses in dogs. J Am Vet Med Assoc. 237(6), 673-81.

DOI: https://doi.org/10.2460/javma.237.6.673

33. Sueda, K. L. \& Malamed, R. (2014). Canine aggression toward people: a guide for practitioners. Vet Clin North Am Small Anim Pract. 44(3), 599-628. DOI: https://doi.org/10.1016/j.cvsm.2014.01.008

34. Taborsky, M. (2010). Sample size in the study of behaviour. Ethology. 116(3), 185-202. DOI: https://doi.org/10.1111/j.1439-0310.2010.01751.x

35. Taylor, S., Webb, L., Montrose, V. T. \& Williams, J. (2020). The behavioral and physiological effects of dog appeasing pheromone on canine behavior during separation from the owner. Journal of Veterinary Behavior. 40(November-December), 36-42.

DOI: $\underline{\text { https://doi.org/10.1016/i.jveb.2020.08.001 }}$

36. Tiira, K., Sulkama, S. \& Lohi, H. (2016). Prevalence, comorbidity, and behavioral variation in canine anxiety. Journal of Veterinary Behavior. 16(November-December), 36-44.

DOI: https://doi.org/10.1016/i.jveb.2016.06.008

37. Wemelsfelder, F. (2001). The Inside and Outside Aspects of Consciousness: Complementary Approaches to the Study of Animal Emotion. Animal Welfare. 10(1), 129-139.

DOI: https://www.ingentaconnect.com/content/ufaw/aw/2001/00000010/a00101s1/art00012 [Acces sed 07 Aug 2020] 


\section{EVIIDEFeE

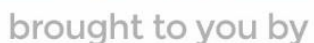 \\ RCVS KNOWLEDGE}

\section{Intellectual Property Rights}

Authors of Knowledge Summaries submitted to RCVS Knowledge for publication will retain copyright in their work, and will be required to grant RCVS Knowledge a non-exclusive license of the rights of copyright in the materials including but not limited to the right to publish, re-

publish, transmit, sell, distribute and otherwise use the materials in all languages and all media throughout the world, and to license or permit others to do so.

\section{Disclaimer}

Knowledge Summaries are a peer-reviewed article type which aims to answer a clinical question based on the best available current evidence. It does not override the responsibility

of the practitioner. Informed decisions should be made by considering such factors as individual clinical expertise and judgement along with patient's circumstances and owners' values. Knowledge Summaries are a resource to help inform and any opinions expressed within the Knowledge Summaries are the author's own and do not necessarily reflect the view of the RCVS Knowledge. Authors are responsible for the accuracy of the content. While the

Editor and Publisher believe that all content herein are in accord with current recommendations and practice at the time of publication, they accept no legal responsibility

for any errors or omissions, and make no warranty, express or implied, with respect to material contained within.

For further information please refer to our Terms of Use.

RCVS Knowledge is the independent charity associated with the Royal College of Veterinary Surgeons (RCVS). Our ambition is to become a global intermediary for evidence based veterinary knowledge by providing access to information

that is of immediate value to practicing veterinary professionals and directly contributes to evidence based clinical decision-making.

https://www.veterinaryevidence.org/

RCVS Knowledge is a registered Charity No. 230886.

Registered as a Company limited by guarantee in England and Wales No. 598443.

Registered Office: Belgravia House, 62-64 Horseferry Road, London SW1P 2AF

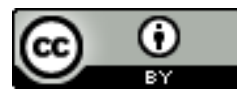

This work is licensed under a Creative Commons Attribution 4.0 International License 